\title{
Excited States of Water-Soluble Metal Porphyrins as Microenvironmental Probes for DNA and DNA-Model Compounds: Time-Resolved Transient Absorption and Resonance Raman Studies of Ni(TMpy-P4) in $[\text { Poly(dG-dC) }]_{2}$ and $[\operatorname{Poly}(\mathrm{dA}-\mathrm{dT})]_{2}$
}

\author{
Victor A. Galievsky and Vladimir S. Chirvony \\ Institute of Molecular and Atomic Physics, Academy of Sciences of Belarus, 70 F. Skaryna Avenue, \\ Minsk 220072, Belarus
}

\author{
Sergei G. Kruglik, Vladimir V. Ermolenkov, and Valentine A. Orlovich \\ B. I. Stepanov Institute of Physics, Academy of Sciences of Belarus, 70 F. Skaryna Avenue, \\ Minsk 220072, Belarus
}

\section{Cees Otto}

University of Twente, Department of Applied Physics, P.O. Box 217, 7500 AE Enschede, The Netherlands

\author{
Peter Mojzes ${ }^{\dagger}$ and Pierre-Yves Turpin* \\ Universite Pierre et Marie Curie, LPBC (CNRS URA 2056), B. 138, 4 place Jussieu, \\ 75252 Paris Cedex 05, France
}

Received: February 27, 1996; In Final Form: April 30, $1996^{\otimes}$

\begin{abstract}
The dynamics and mechanisms of photoexcitation relaxation of the water-soluble cationic metalloporphyrin nickel(II) $5,10,15,20$-tetrakis[4-( $N$-methylpyridyl)]porphyrin (Ni(TMpy-P4)) bound to DNA-model polynucleotides, i.e. poly $(\mathrm{dG}-\mathrm{dC})_{2}$ and poly $(\mathrm{dA}-\mathrm{dT})_{2}$, and free in a mere phosphate buffer, have been studied in detail by using time-resolved picosecond transient absorption (TA) and nanosecond resonance Raman (RR) spectroscopies. For the Ni(TMpy-P4) - poly (dG-dC $)_{2}$ complex, double-exponential kinetics of relaxation has been found, with time constants of $\leq 10$ and $350 \pm 20 \mathrm{ps}$, and absolute absorption spectra have been reconstructed from experimentally measured difference spectra. The long-lived transient species has been assigned to the excited intramolecular metal-centered (d,d) state ${ }^{3} \mathrm{~B}_{1 \mathrm{~g}}$ of the 4-coordinate Ni porphyrin intercalated between G-C base pairs. Transient RR spectra originating from this state have also been obtained and discussed. A much more complicated process of excitation relaxation has been found for the $\mathrm{Ni}(\mathrm{TMpy}-$ P4) - poly(dA-dT $)_{2}$ complex, where at least four relaxation components can be separated with time constants of $\leq 10, \sim 100, \sim 450 \mathrm{ps}$, and $\gg 1 \mathrm{~ns}$. Our studies support the existence of at least two types of Ni(TMpy-P4) interaction with poly $(\mathrm{dA}-\mathrm{dT})_{2}$, each having its own kinetics of TA decay and transient RR spectra. Both TA and RR sets of data show that a major part of Ni porphyrin molecules yields a photophysical behavior typical for a 4-coordinate species, the excited $(\mathrm{d}, \mathrm{d})$ state ${ }^{3} \mathrm{~B}_{1 \mathrm{~g}}$ playing the key role in relaxation processes, while a minor part of Ni(TMpy-P4) also participates in axial ligand binding/release photoprocesses. Comparative analysis of transient RR spectra of $\mathrm{Ni}(\mathrm{TMpy}-\mathrm{P} 4)$ bound to the A-T sequence and free in a phosphate buffer shows that no 6-coordinate ${ }^{3} \mathrm{~B}_{1 \mathrm{~g}}(\mathrm{~L})_{2}$ transient species is photogenerated in the complex with poly $(\mathrm{dA}-\mathrm{dT})_{2}$, and therefore, axial coordination of only one extra-ligand molecule (most probably from the surrounding water solution) to the porphyrin central $\mathrm{Ni}$ ion is proposed to explain the experimental results. Possible processes of $\mathrm{Ni}(\mathrm{TMpy}-\mathrm{P} 4)$ binding to poly $(\mathrm{dA}-\mathrm{dT})_{2}$ are discussed on the basis of the current photophysical data.
\end{abstract}

\section{Introduction}

Since the pioneering work of Fiel et al., ${ }^{1}$ interactions of watersoluble cationic porphyrins with DNA attracted a growing interest, ${ }^{2-8}$ in the perspective of their possible biomedical applications. Indeed, these molecules, being intercalated in or outside bound to DNA, are known as models for anticancer drugs $^{5,9,10}$ and as photosensitizers in photodynamic therapy of cancer. ${ }^{11-14}$ Furthermore it has been recently found that porphyrins can inhibit HIV-1, the virus responsible for AIDS. ${ }^{15-17}$

* Author to whom correspondence should be sent. e-mail: turpin@1pbc.jussieu.fr.

$\dagger$ Permanent address: Institute of Physics, Charles University, Ke Karlovu 5, CZ-12116, Prague 2, Czech Republic.

${ }^{\otimes}$ Abstract published in Advance ACS Abstracts, June 15, 1996.
Until recently, excited-state properties of porphyrins bound to DNA have been only related to their ability to bring about DNA photocleavage, most likely through singlet oxygen generation. ${ }^{5,12,13,18}$ For biomedical applications, porphyrins which exhibit efficiently populated and long-lived excited $\left(\pi, \pi^{*}\right)$ triplet states, e.g. $\mathrm{H}_{2}$ (TMpy-P4) and its $\mathrm{Zn}$ derivative, are of highest interest. However, from the point of view of specific interactions with nucleic acids, porphyrins substituted by transition metals can present even greater interest, in spite of their eventually short (subnanosecond) excited state lifetimes. ${ }^{19-22}$ This interest lies in their ability to promote photoinduced axial ligand(s) attachment and/or release via metal-centered $(\mathrm{d}, \mathrm{d})$ and charge transfer $(\mathrm{CT})\left(\mathrm{d}, \pi^{*}\right)$ or $(\pi, \mathrm{d})$ electronic excited states. 
Besides these photochemical reactions, it is reasonable to suggest that pure intramolecular photophysical processes, occurring via these states, can also depend on properties of the surrounding medium, e.g. local polarity, because energies of the metal-centered CT and $(\mathrm{d}, \mathrm{d})$ excited states depend on the local intensity of the electric field. Therefore, studies of transition-metal porphyrins specifically incorporated into nucleic acids and model polynucleotides can give, in principle, important information about the porphyrin local environment.

A first observation of such a specific photoreaction has been made in 1990 for the $\mathrm{Cu}$ (TMpy-P4)-DNA complex. ${ }^{23}$ In this work, besides porphyrin ground-state vibrational lines, new lines have been found in RR spectra obtained at high excitation intensities by using 10-ns laser pulses: these additional lines have been assigned to an exciplex formed between photoexcited $\mathrm{Cu}$ (TMpy-P4) and DNA. Further RR studies, carried out with various DNA and DNA-model compounds, ${ }^{24-27}$ have proven the crucial role of DNA AT sites and of the flexibility of PuPy alternating double-helical structures for the exciplex formation. In addition, the involvement of a carbonyl $\mathrm{CO}$ group from thymine or uracil residues as an axial ligand for $\mathrm{Cu}(\mathrm{TMpy}-\mathrm{P} 4)$ in exciplex formation has been suggested, on the basis of RR studies of various DNA-model oligo- and polynucleotides. ${ }^{26,27}$ An electronic origin of the exciplex has been proposed, in terms of an excited transient $(\mathrm{d}, \mathrm{d})$ state of a 5-coordinate $\mathrm{Cu}$ porphyrin, ${ }^{26}$ on the basis of comparison with a similar process of exciplex formation between photoexcited non-water-soluble $\mathrm{Cu}$ (II) porphyrins ( $\mathrm{CuOEP}$ and $\mathrm{CuTPP}$ ) and oxygen-containing $\sigma$-donor solvent molecules, such as tetrahydrofuran and 1,4dioxane. ${ }^{21,22}$

Finally, time-resolved picosecond TA and RR measurements of $\mathrm{Cu}(\mathrm{TMpy}-\mathrm{P} 4)-$ poly $(\mathrm{dA}-\mathrm{dT})_{2}$ complexes $^{28}$ supported this suggestion and showed that binding of a $\mathrm{CO}$ group of thymine as an axial ligand to the 4-coordinate $\mathrm{Cu}$ (TMpy-P4) occurs in the porphyrin triplet $\left(\pi, \pi^{*}\right)$ excited state. Quenching of the latter occurs with a time constant of $35 \mathrm{ps}$ to populate a downward shifted excited $(\mathrm{d}, \mathrm{d})$ state, this last being the key exciplex state and having a lifetime of $3.2 \mathrm{~ns}$. It is worth note that, for such an exciplex to be created, specific geometrical positions of $\mathrm{Cu}(\mathrm{TMpy}-\mathrm{P} 4)$ versus $\mathrm{T}$ (or $\mathrm{U}$ ) residues are required, as well as proper secondary structure and flexibility of the polymer. Therefore, the study of such an exciplex provides important structural information about the porphyrin-polynucleotide interactions.

Furthermore, additional information about the excited-state properties of metalloporphyrin can be expected in considering that, under the conditions of $\mathrm{Cu}(\mathrm{TMpy}-\mathrm{P} 4)-$ poly $(\mathrm{dA}-\mathrm{dT})_{2}$ exciplex formation, photoexcited $\mathrm{Cu}(\mathrm{TMpy}-\mathrm{P} 4)$ is not accessible (at least the major part of it) to the quenching influence of surrounding water molecules. This contrasts with the case of free $\mathrm{Cu}(\mathrm{TMpy}-\mathrm{P} 4)$ in a mere phosphate buffer, where the metalloporphyrin excited states are efficiently quenched directly to the ground state by water molecules, with a time-constant of tens of picosecond. ${ }^{28}$

The purpose of the present study is to investigate the photoinduced behavior of a cationic metalloporphyrin containing another transition metal, i.e. Ni(TMpy-P4), bound to DNAmodel polynucleotides poly $(\mathrm{dG}-\mathrm{dC})_{2}$ and poly $(\mathrm{dA}-\mathrm{dT})_{2}$. Ni(II) porphyrins are considered for a long time as exemplary systems for elucidating both ground-state properties and excitedstate features involved in the relaxation processes of metalloporphyrin complexes. Structure of the excited states, relaxation pathways, and rate constants of non-water-soluble $\mathrm{Ni}$ (II) porphyrins have been comprehensively investigated in numerous studies using time-resolved transient absorption ${ }^{19,20,29-35}$ and

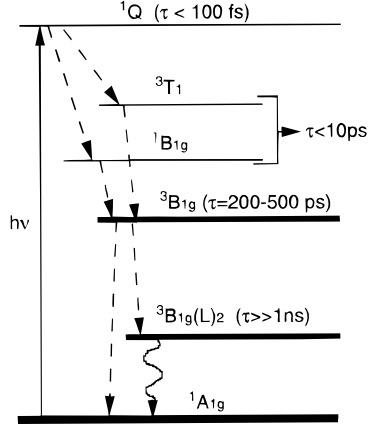

(A) Excitation of four-coordinate NiP

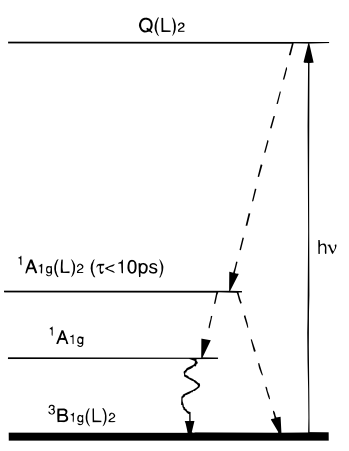

(B) Excitation of six-coordinate NiP
Figure 1. Schematic diagram of the main electronic states and possible relaxation pathways for $\mathrm{Ni}(\mathrm{II})$ porphyrins $(\mathrm{NiP})$ : (A) $\mathrm{Ni}$ is 4-coordinate in the NiP ground state, and (B) $\mathrm{Ni}$ is 6-coordinate in the $\mathrm{NiP}$ ground state, having two ligands (L) attached. Broken line arrows indicate relaxation pathways of excited electronic states. Waved lines indicate relaxation of photoinduced thermodynamically nonequilibrated 6-coordinate (for scheme A) and 4-coordinate (for scheme B) ground state species. For some states, lifetimes are indicated, if known from the literature. For more details see refs 30-35, 42, 44.

resonance Raman/CARS ${ }^{21,36-41}$ spectroscopies. The nickel excited d-electron configuration $\left(\mathrm{d}_{z^{2}}, \mathrm{~d}_{x^{2}-y^{2}}\right)$ arising from the promotion of an electron from the inner filled $\mathrm{d}_{z}{ }^{2}$ to the upper unfilled $\mathrm{d}_{x^{2}-y^{2}}$ metal orbitals ${ }^{42}$ gives rise to low-lying singlet ${ }^{1} \mathrm{~B}_{1 \mathrm{~g}}$ and triplet ${ }^{3} \mathrm{~B}_{1 \mathrm{~g}}$ metal-centered excited states, which are the key states in the photophysics of 4-coordinate $\mathrm{Ni}$ porphyrins (Figure 1A). Theoretical calculations ${ }^{42}$ have shown that, for all 4-coordinate (diamagnetic) Ni porphyrins and whatever the porphyrin ligand, $(\mathrm{d}, \mathrm{d})$ excited states lie considerably below the lowest excited $\left(\pi, \pi^{*}\right)$ singlet ${ }^{1} \mathrm{Q}$ and triplet ${ }^{3} \mathrm{~T}$ electronic states. Although the exact energy positions of the ${ }^{1} B_{1 \mathrm{~g}}$ and ${ }^{3} \mathrm{~B}_{1 \mathrm{~g}}$ states are unknown, triplet-triplet energy transfer experiments have indicated ${ }^{43}$ that the ${ }^{3} \mathrm{~B}_{1 \mathrm{~g}}$ state lies lower than $9000 \mathrm{~cm}^{-1}$.

A lack of emission from the ${ }^{1} \mathrm{Q}\left(\pi, \pi^{*}\right)$ state of Ni porphyrins ${ }^{44}$ results from its ultrafast radiationless deactivation via the $(d, d)$ electronic level subsystem. It has been found that for all of the 4-coordinate Ni porphyrins, excited (d,d) state is populated from upper-lying $\left(\pi \rightarrow \pi^{*}\right)$ excited states within less than $50 \mathrm{fs}$, as indirectly estimated from helium temperature absorption bandwidths by using the uncertainty relationship. ${ }^{45}$ Subsequent excitation relaxation proceeds with a biphasic kinetics. The properties of the lowest and long-lived $(\mathrm{d}, \mathrm{d})$ excited state (hundreds of $\mathrm{ps}$ ), presumably a $\left({ }^{3} \mathrm{~B}_{1 \mathrm{~g}}\right)$ triplet state, have already been settled for non-water-soluble Ni(II) porphyrins. ${ }^{19-21,29-41}$ The nature of the short-lived transient species (lifetime $\leq 10$ ps) is still currently under debate. Earlier studies proposed that this transient species may originate from different excited electronic states, ${ }^{1} \mathrm{Q}\left(\pi, \pi^{*}\right),{ }^{29}{ }^{3} \mathrm{~T}_{1}\left(\pi, \pi^{*}\right),{ }^{30,31}$ or ${ }^{1} \mathrm{~B}_{1 \mathrm{~g}}(\mathrm{~d}, \mathrm{~d}) .{ }^{32,33}$ More recently, Rodriguez et al. ${ }^{34,35}$ explained this fast relaxation process by the cooling of vibrationally hot $(\mathrm{d}, \mathrm{d})$ excited states, on the basis of femtosecond transient absorption studies. Meanwhile, Courtney et al. ${ }^{39}$ proposed a mechanism of fast conformational relaxation, on the basis of narrowing of the porphyrin marker lines in transient RR spectra. Recent timeresolved RR studies of NiOEP by Sato and Kitagawa ${ }^{40}$ confirmed the existence of vibrationally hot $(d, d)$ excited states; however, possible contribution from the conformational relaxation was not completely ruled out in this study. At last, a recent saturation nanosecond resonance CARS study of $\mathrm{NiOEP}^{41}$ showed that two excited electronic states, presumably ${ }^{1} \mathrm{~B}_{1 \mathrm{~g}}$ and ${ }^{3} \mathrm{~B}_{1 \mathrm{~g}}$, participate in the relaxation processes, since two prominent sets of excited-state Raman lines were found in transient RCARS spectra recorded at high excitation power. Consequently, all the processes mentioned above, i.e. ${ }^{1} \mathrm{~B}_{1 \mathrm{~g}}$ and ${ }^{3} \mathrm{~T}_{1}$ excited-state 
population, vibrational heating/cooling, and conformational changes, likely occur at the early steps of relaxation for $\mathrm{Ni}$ porphyrins. The extent to which each physical mechanism contributes remains to be determined in each particular case.

The photophysical relaxation scheme for 6-coordinate NiP, i.e. $\mathrm{NiP}(\mathrm{L})_{2}$ (Figure $1 \mathrm{~B}$ ), is much less elaborated. It is only known that effective photodissociation of axial ligands occurs within a time interval shorter than $10 \mathrm{ps}$, and the ${ }^{1} \mathrm{~A}_{1 \mathrm{~g}}(\mathrm{~L})_{2}$ state is likely a dissociative state, which results in the formation of the nonequilibrated 4-coordinate ${ }^{1} \mathrm{~A}_{1 \mathrm{~g}}$ ground electronic state, followed by backliganding and formation of the initial (equilibrated) ${ }^{3} \mathrm{~B}_{1 \mathrm{~g}}(\mathrm{~L})_{2}$ ground state. ${ }^{31-33}$

From what precedes it is clear that $\mathrm{Ni}$ porphyrins can be considered as well-investigated molecules. However, the excited-state properties of the water-soluble derivative Ni(TMpyP4) and its complexes with DNA and DNA-model compounds have not been investigated yet. Concerning the ground-state properties of these complexes it is well established that, in aqueous solution, free $\mathrm{Ni}(\mathrm{TMpy}-\mathrm{P} 4)$ exists as an equilibrium mixture of 4- $\left({ }^{1} \mathrm{~A}_{1 \mathrm{~g}}\right)$ and 6-coordinate $\left({ }^{3} \mathrm{~B}_{1 \mathrm{~g}}(\mathrm{~L})_{2}\right)$ ground-state species, two water molecules being axially ligated to the central atom in the latter case. ${ }^{46,47}$ In the presence of an excess of G-C base pairs, e.g. in poly $(\mathrm{dG}-\mathrm{dC})_{2}$, the 6-coordinate species loses its axial water ligands and is converted to the 4-coordinate species, which is subsequently intercalated at the G-C sites. ${ }^{47-49}$ Much more puzzling is the question concerning the type of location for $\mathrm{Ni}(\mathrm{TMpy}-\mathrm{P} 4)$ within poly $(\mathrm{dA}-\mathrm{dT})_{2}$. Unusual circular dichroism ${ }^{47,51,52}$ and $\mathrm{RR}^{49,50}$ features found for this complex supports the existence of at least two different types of interaction: one is a groove-binding mode whereas the second has been assigned to partial intercalation (or stacked aggregation) along isolated regions of the A-T sequence.

In our study, we have used two spectroscopic techniques which well complement each other, i.e. time-resolved picosecond TA and nanosecond saturation RR spectroscopies. These methods have proven their efficiency for investigating excited states of complex organic molecules ${ }^{21,22,28}$ and provide both temporal and structural information about the objects under investigation.

\section{Experimental Section}

Materials. The $\mathrm{Ni}(\mathrm{II})$ derivative of 5,10,15,20-tetrakis(4( $N$-methylpyridyl))porphyrin is a generous gift of K. Nakamoto (Marquette University, Milwaukee WI). Poly $(\mathrm{dA}-\mathrm{dT})_{2}$ and poly $(\mathrm{dG}-\mathrm{dC})_{2}$ were purchased from Pharmacia Biochemicals. All compounds have been used as they came. Sample solutions have been prepared by mixing an aqueous solution of Ni(TMpyP4) with a phosphate buffer solution of the nucleic acids. The final solution thus obtained ( $\mathrm{pH}=6.8$, ionic strength $\mu=0.2$ ) contained porphyrin and nucleic acids (concentration in base pairs for double-stranded polynucleotides) at ca. $3.0 \times 10^{-5}$ and $1.0 \times 10^{-3} \mathrm{M}$, respectively, as determined spectrophotometrically. Thus, the molar ratio of base pairs (residues)/NiP was ca. 30.

Transient Absorption Spectroscopy. Transient absorption spectra and kinetics of absorption changes were measured on a homemade tunable pump-probe absorption spectrometer having a 10-ps time resolution. Pumping was provided by the second harmonic of a $\mathrm{YAlO}_{3}: \mathrm{Nd}$ solid-state master laser $\left(\lambda_{\text {pump }}=540\right.$ $\mathrm{nm}$ ), while the output beam of an optical parametric oscillator was used as a probing beam tunable over the entire visible region (360-1000 nm). An intracavity negative-feedback electrooptical system, in combination with the intracavity pulse selection, provided a high laser intensity stability (intensity dispersion < $2 \%$ ) and resulted in sufficiently high sensivity and accuracy of the spectrometer $\left(3 \times 10^{-4}\right.$ OD units $)$.
Resonance Raman Spectroscopy. RR spectra were recorded several times, independently at three different nanosecond Raman spectrometers available in our laboratories in Minsk, ${ }^{22}$ Paris, ${ }^{26}$ and Enschede. ${ }^{53}$ All systems were based on Q-switched $\mathrm{Nd}$ :YAG lasers, used as pump source for other laser devices such as dye lasers, Raman shifters, and frequency mixers. All Raman spectra were collected in using nearly backscattering geometries. The samples were contained either in a rotating cell with $1 \mathrm{~mm}$ thickness or in a stirring standard spectrophotometric cell. Raman scattering signal was dispersed either by a double diffraction DFS-52 22 and Jobin-Yvon HG2S ${ }^{26}$ monochromator (in the case of single-channel detection system) or by the Spex Triplemate 1877 polychromator in combination with a PAR-1421 multichannel array detector. ${ }^{53}$ Spectral resolution in all experiments was typically ca. $5-7 \mathrm{~cm}^{-1}$. Laser radiation was focused by a spherical lens of $f=25 \mathrm{~cm}$ focal length. Variation of excitation intensity was obtained by changing both the diameter of the illuminated spot on the sample cell and the energy of the laser beam by using neutral density filters and apertures.

All experiments were performed at ambient temperature or $4{ }^{\circ} \mathrm{C}$. All photoinduced spectral changes reported in the present work were completely reversible, and no accumulation of stable new forms was found. The absence of sample degradation was checked before and after laser experiments by recording stationary absorption spectra.

\section{Results}

1. Transient Absorption and Kinetics. Porphyrin in a $G-C$ Sequence. Excitation of the Ni(TMpy-P4)-poly(dG-dC) $)_{2}$ complex with 10-ps laser pulses at $540 \mathrm{~nm}$ resulted in fully reversible optical density (OD) changes observable in the 390-470 nm spectral region corresponding to the porphyrin Soret band. Typical kinetics of OD changes are biphasic and can be well fitted by double-exponential functions, with time constants of $\leq 10 \mathrm{ps}$ and $350 \pm 20 \mathrm{ps}$. An example of such a typical twocomponent kinetics is shown in Figure $2 \mathrm{~A}$, recorded at $\lambda_{\text {probe }}=$ $432 \mathrm{~nm}$. According to the properties of isosbestic points, selected wavelengths can also be found where only the first or second decay component are separately detected (curves $2 \mathrm{~B}$ and $2 \mathrm{C}$ recorded at 437.5 and $444 \mathrm{~nm}$, respectively).

To reconstruct the absolute absorption spectra of both shortlived and long-lived transient species from their experimental difference spectra (not shown), we estimated the percentage of probed molecules which is pumped from the ground to the corresponding transient states. This has been done by measuring the dependence of the observed OD changes for both components (i.e. at different time delays) as a function of the pumping energy $E_{\text {pump. }}$.

(i) For the long-lived transient species (OD changes measured at 50-ps delay) a saturation curve of OD changes as a function of $E_{\text {pump }}$ has been obtained, which shows a plateau for pumping energy densities $E_{\text {pump }} \geq 50 \mathrm{~mJ} / \mathrm{cm}^{2}$; about $100 \%$ of the molecules are thus pumped into the second (long-lived) transient state for pumping densities greater than this threshold. Since we routinely used $E_{\text {pump }} \simeq 100 \mathrm{~mJ} / \mathrm{cm}^{2}$, we can simply add the measured OD changes for the second transient species, i.e. $\Delta \mathrm{OD}_{2}(\lambda)$, to the ground state absorption spectrum $\mathrm{A}_{\mathrm{g}}(\lambda)$ to obtain the absolute absorption spectrum $\mathrm{A}_{2}(\lambda)$ of the second (long-lived) transient species.

(ii) As for the first (short-lived) transient species, only near-saturation conditions have been achieved for this species (OD changes measured at 5-ps delay) even at pumping density $E_{\text {pump }} \cong 200 \mathrm{~mJ} / \mathrm{cm}^{2}$. Consequently, since we have used a similar expression to reconstruct its absolute absorption 


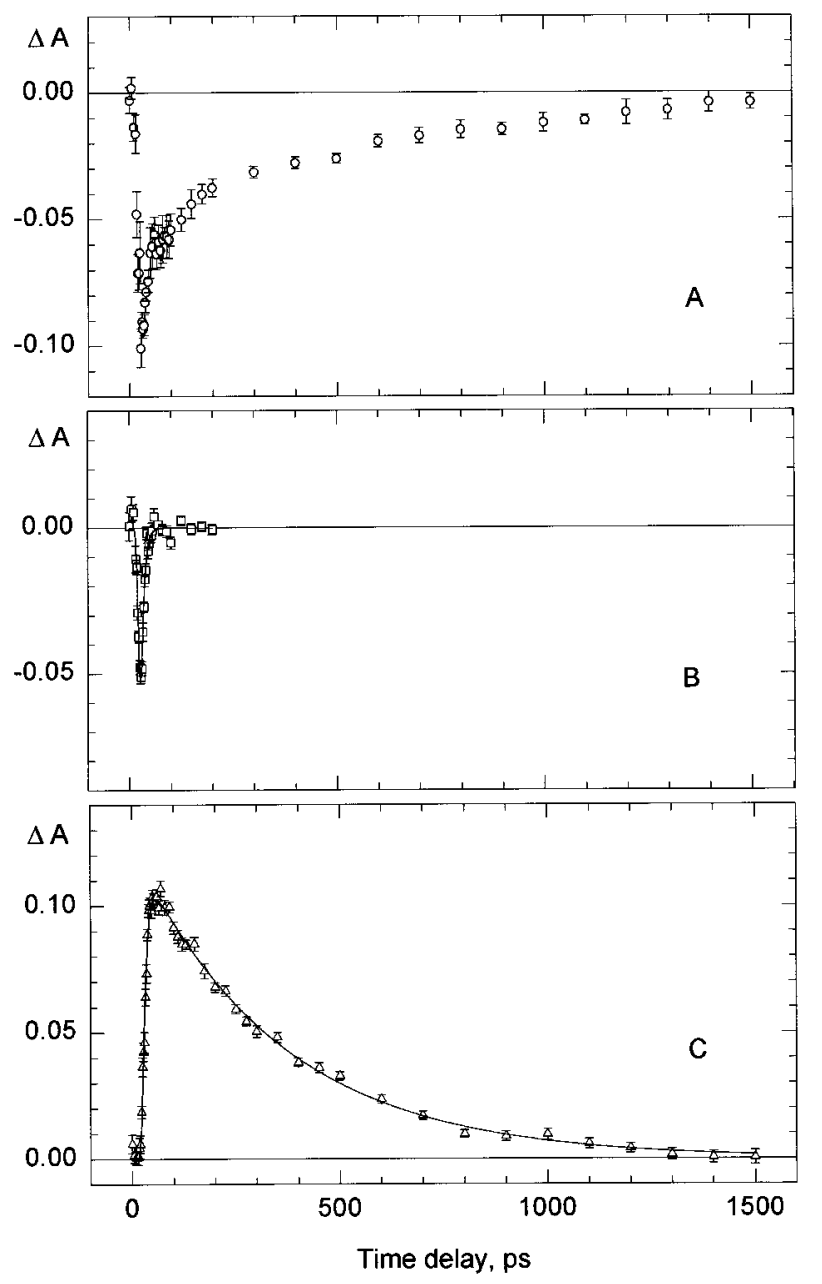

Figure 2. Time evolution of OD changes of Ni(TMpy-P4)-poly(dGdC) $)_{2}$ complex probed at different wavelengths: 432 (A), 437.5 (B), and $444 \mathrm{~nm}(\mathrm{C})$. Solid line curves B and C represent least-squares fits by single-exponential functions having time constants of 10 and 350 $\pm 20 \mathrm{ps}$, respectively. Pumping was provided by a radiation flux of $\sim 100 \mathrm{~mJ} / \mathrm{cm}^{2}$ at $540 \mathrm{~nm}$. The maximum standard deviation in $\Delta A$ is 0.003 .

spectrum $A_{1}(\lambda)$, i.e.

$$
\mathrm{A}_{1}(\lambda)=\mathrm{A}_{\mathrm{g}}(\lambda)+\Delta \mathrm{OD}_{1}(\lambda)
$$

with $\Delta \mathrm{OD}_{1}(\lambda)$ obtained at 5-ps delay and $E_{\text {pump }} \cong 100 \mathrm{~mJ} / \mathrm{cm}^{2}$, it is necessary to keep in mind that this spectrum also contains some small contribution of the ground state absorption.

The reconstructed transient absorption spectra $A_{1}(\lambda)$ and $A_{2}-$ $(\lambda)$ are shown in parts A and B, respectively, of Figure 3, along with the ground-state absorption profile in the Soret-band region (curve 3C).

Porphyrin in a A-T Sequence. Much more complicated OD decay kinetics have been observed within the Soret-band region after excitation of the Ni(TMPy-P4)-poly(dA-dT) $)_{2}$ complex with 10-ps laser pulses at $540 \mathrm{~nm}$. Observed decay profiles were strongly dependent on the probing wavelength; some of those are presented in Figure 4A-C. They obviously are too complicated to allow any quantitative kinetic analysis to be carried out. However, qualitative analysis of the kinetic profiles shows that at least four transient species participate in the excitation energy relaxation, whose time constants have the following approximate values: $\leq 10 \mathrm{ps}, \sim 100 \mathrm{ps}, \sim 450 \mathrm{ps}$, and $>1$ ns. Figure 5 shows absolute absorption spectra reconstructed for the first (curve 5A, delay 5 ps), second (curve 5B, delay 50 ps), and fourth (curve 5C, delay $1 \mathrm{~ns}$ ) transient forms, according

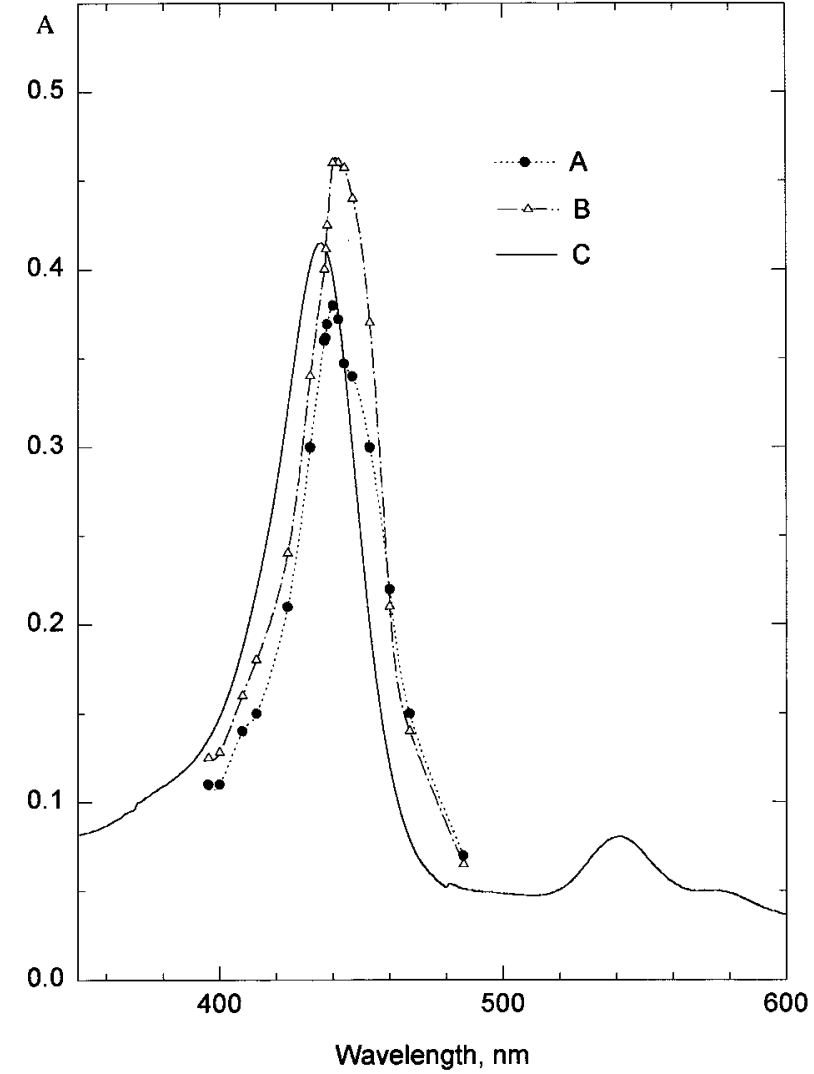

Figure 3. Ground-state absorption spectrum of Ni(TMpy-P4)-poly$(\mathrm{dG}-\mathrm{dC})_{2}$ (curve $\mathrm{C}$ ) and its reconstructed transient absorption spectra at time delays of $5 \mathrm{ps}$ (A) and $50 \mathrm{ps}(\mathrm{B})$ after pulsed excitation at 540 $\mathrm{nm}$. A and B absorption spectra correspond to transient species having lifetimes of $\leq 10$ and $350 \pm 20 \mathrm{ps}$, respectively.

to the method described above, for a pumping energy density of $E_{\mathrm{pump}} \cong 100 \mathrm{~mJ} / \mathrm{cm}^{2}$. The TA spectrum obtained for the third transient form is omitted to avoid overloading of the figure with details, because TA spectra of the second and third components were found to be very close to each other. Like in the case of the Ni(TMpy-P4)-G-C complex (Figure 3), the 5 -ps delay spectrum of $\mathrm{Ni}(\mathrm{TMpy}-\mathrm{P} 4)-$ poly $(\mathrm{dA}-\mathrm{dT})_{2}$ contains some contribution from the ground state absorption. On the other hand, the spectral shape of the profile of the fourth transient spectrum, obtained at 1-ns delay after excitation (Figure $5 \mathrm{C}$ ), suggests that this absolute spectrum may contain a nonnegligible contribution from the ground-state absorption.

Porphyrin in Water. As mentioned earlier, Ni(TMpy-P4) in mere water buffer exists in the ground electronic state as a mixture, in nearly equal proportions, of 4- and 6-coordinate species. Excitation at $540 \mathrm{~nm}$ certainly involves both forms, and thus the observation of complicated decay kinetics of OD changes is not surprising. Some of these kinetics are presented in Figure 6. Although particular profiles are strongly dependent on probing wavelength, we determined at least three monoexponential decay components having time constants $\leq 10$ ps (curve 6A), $300 \pm 20$ ps (curve 6B), and $\gg 1$ ns (curve 6C).

2. Transient Resonance Raman Spectra. Porphyrin in a $G-C$ Sequence. Figure 7 shows unsmoothed RR spectra of Ni(TMpy-P4) in the presence of poly $(\mathrm{dG}-\mathrm{dC})_{2}$, recorded with 436 $\mathrm{nm}$ excitation (i.e. into the Soret band), and with increasing laser power densities from spectrum $7 \mathrm{~A}\left(10^{6} \mathrm{~W} / \mathrm{cm}^{2}\right)$ to spectrum 7D (ca. $10^{8} \mathrm{~W} / \mathrm{cm}^{2}$ ). In the low-power RR spectrum (Figure 7A), the well-known ground-state porphyrin Raman bands $v_{2}\left(1585 \mathrm{~cm}^{-1}\right), v_{3}\left(1480 \mathrm{~cm}^{-1}\right)$, and $v_{4}\left(1377 \mathrm{~cm}^{-1}\right)$ as well as the methylpyridyl Raman band at $1644 \mathrm{~cm}^{-148,54}$ dominate. As the excitation density increases, new photoin- 


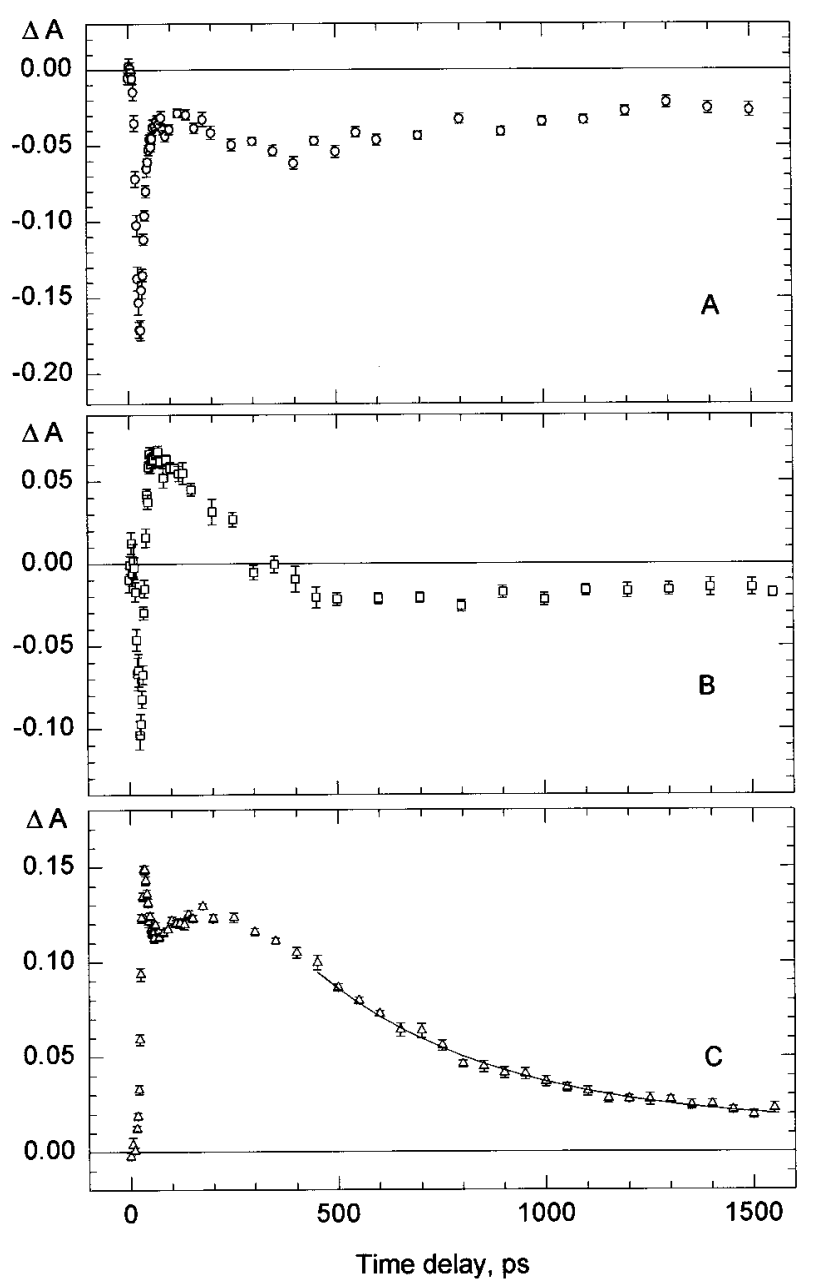

Figure 4. Time evolution of OD changes of Ni(TMpy-P4) - poly(dA$\mathrm{dT})_{2}$ complex probed at different wavelengths: 423 (A), 426 (B), and $446 \mathrm{~nm}(\mathrm{C})$. Solid line curve $\mathrm{C}$ represents a least-squares fit to a singleexponential function with $450 \pm 30$ ps time constant.

duced transient Raman bands also increase, appearing as lowfrequency satellites of the ground-state bands which in turn become much weaker, i.e. $1585 \leftrightarrow 1563 \mathrm{~cm}^{-1}, 1480 \leftrightarrow 1459$ $\mathrm{cm}^{-1}$, and $1376 \leftrightarrow 1363 \mathrm{~cm}^{-1}$, while the methylpyridyl Raman band remains practically unaltered.

Porphyrin in a A-T Sequence. Transient RR spectra of Ni(TMpy-P4) bound to poly $(\mathrm{dA}-\mathrm{dT})_{2}$ (Figure 8), recorded under the same experimental conditions as for Figure 7, reveal very similar photoinduced changes, with pairs of porphyrin marker bands originating from both the ground and photoinduced transient excited states. However, a more careful examination allows slight differences between spectra of $\mathrm{Ni}$ porphyrin-poly$(\mathrm{dG}-\mathrm{dC})_{2}$ and - poly $(\mathrm{dA}-\mathrm{dT})_{2}$ complexes to be found, the most pronounced one being the presence of a $1468 \mathrm{~cm}^{-1}$ second satellite of the $v_{3}$ band in the latter case (see Discussion for details).

Transient RR spectra of Ni(TMpy-P4)-poly(dG-dC) 2 complex recorded with excitations at 427 and $416 \mathrm{~nm}$ and of Ni(TMpy-P4)-poly(dA-dT) $)_{2}$ complex recorded with $416 \mathrm{~nm}$ excitation (spectra not shown) reveal the same peculiarities as those of Figures 7 and 8 . It should be noted that in one of our previous papers, ${ }^{23}$ apart from a noticeable intensity decrease of the ground-state lines corresponding to some ground state depletion at "high" power density, any photoinduced spectral changes in RR spectra of Ni(TMpy-P4) bound to A-T sequence were reported. However, our present results unambiguously prove the existence of a new transient species in this complex created at sufficiently high excitation density: Raman spectra

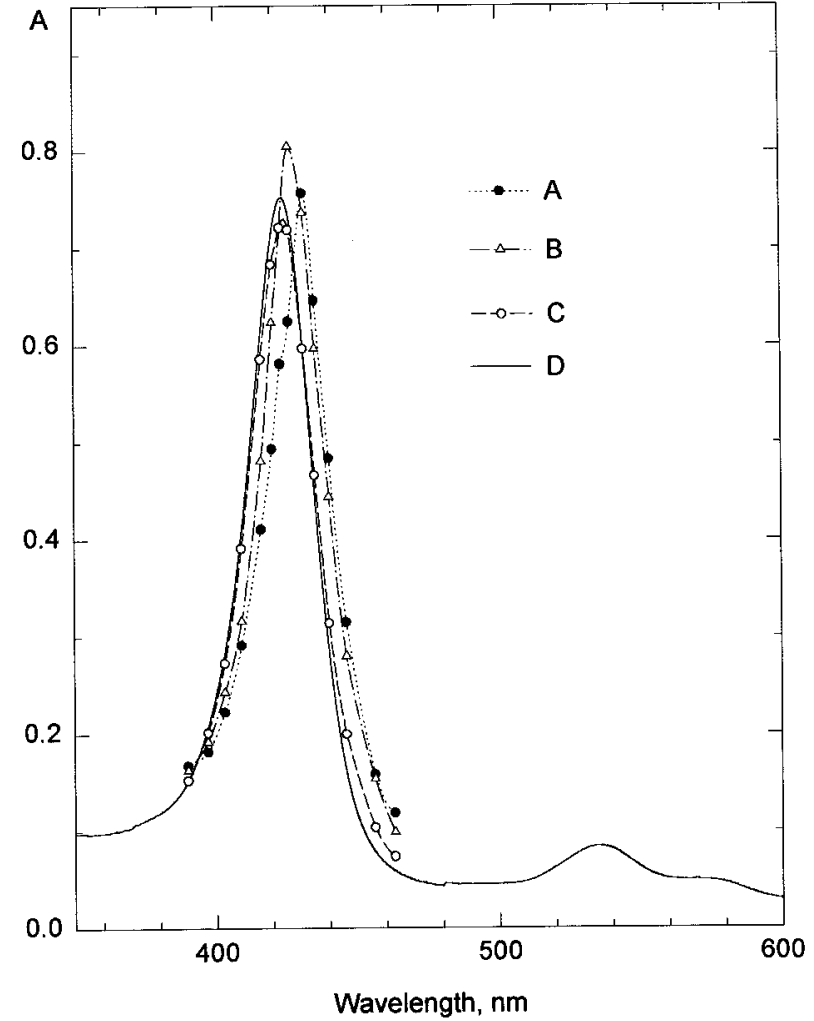

Figure 5. Ground-state absorption spectrum of Ni(TMpy-P4)-poly$(\mathrm{dA}-\mathrm{dT})_{2}$ (curve D) and its reconstructed transient absorption spectra at time delays of 5 ps (A), 50 ps (B), and 1000 ps (C) after pulsed excitation at $540 \mathrm{~nm}$.

were recorded independently several times at three different laboratories, and in all cases the results were as presented in Figures 7 and 8 . Presumably, the failure of previous attempts to observe such photoinduced changes was due to unconvenient excitation power density.

To test the dynamics of the complexes in intense nanosecond laser field, a special experiment was carried out in which porphyrin Raman marker line $v_{2}$ at ca. $1585 \mathrm{~cm}^{-1}$, its excitedstate counterpart $v_{2}^{*}$ at ca. $1561 \mathrm{~cm}^{-1}$, and methylpyridyl line at ca. $1644 \mathrm{~cm}^{-1}$ were normalized on the water band at ca. 3450 $\mathrm{cm}^{-1}$ in RR spectra recorded at low (Figure 9A,C) and high (Figure 9B,D) excitation densities. For this purpose only two spectral ranges of interest, i.e. $1500-1700$ and 2500-4000 $\mathrm{cm}^{-1}$, were scanned in a standard acquisition mode with small $\left(1 \mathrm{~cm}^{-1}\right)$ and large $\left(5 \mathrm{~cm}^{-1}\right)$ steps, respectively. It is clearly seen in Figure $9 \mathrm{~A}-\mathrm{D}$ that, in increasing excitation power, ground-state Raman band $v_{2}$ is transformed into its excitedstate low frequency counterpart $v_{2}{ }^{*}$, both lines having comparable intensities, eventually. This supports the assumption that almost full conversion of Ni(TMpy-P4) molecules occurs, some kind of "switching" between the ground and transient excited states reflected in the $v_{2}$ and $v_{2} *$ lines, respectively, and that no other transient state measurably contributes to this process. Note also that both pairs of RR spectra, i.e. 9A and 9C on one hand, 9B and 9D on the other, have been recorded under the same intensity levels of excitation.

Porphyrin in Water. Since TA experiments have proven the presence of a long-lived ( $\gg 1 \mathrm{~ns}$ ) relaxation component in the $\mathrm{Ni}(\mathrm{TMpy}-\mathrm{P} 4)-$ poly(dA-dT $)_{2}$ complex, which supports the existence of some binding/release photoprocesses, comparative RR studies have been performed for free Ni(TMpy-P4) in a mere phosphate buffer, where it exists in its ground electronic state as a nearly equal mixture of 4- and 6-coordinate species. Figure 9 also shows RR spectra of this free Ni(TMpy-P4) within 


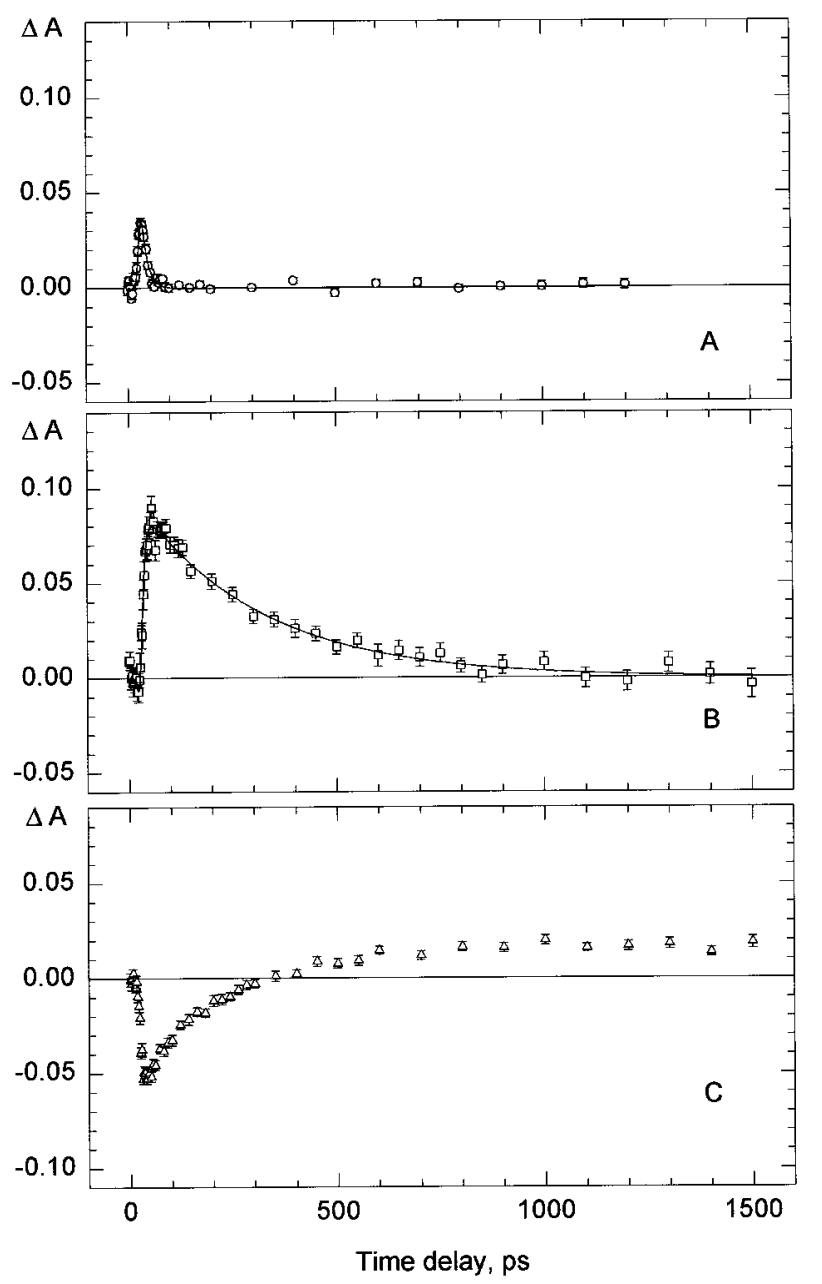

Figure 6. Time evolution of OD changes for free Ni(TMpy-P4) in a phosphate buffer observed at probing wavelengths 480 (A), 430 (B), and $443 \mathrm{~nm}(\mathrm{C})$. Solid line curves A and B represent least-squares fits to single-exponential functions having time constants of 10 and $300 \pm$ $20 \mathrm{ps}$, respectively.

the $v_{2}$ line region, recorded at $418 \mathrm{~nm}$ excitation, i.e. close to the absorption maximum of the 4-coordinate species, and at low and high excitation powers (Figure 9E,F, respectively). On the other hand, Figure 10 shows the RR spectra within the $v_{4}$ line region, obtained with excitation at $436 \mathrm{~nm}$, i.e. close to the absorption maximum of the 6-coordinate form of free Ni(TMpyP4). Again, all experimental conditions (geometry, focusing conditions, and excitation density) were maintained the same for the pairs of spectra of Figure 10A and 10C (low density) and 10B and 10D (high density), respectively.

Summarized frequency data of Ni(TMpy-P4) Raman marker lines in different molecular environments, recorded with excitations at 416, 418, 427, and $436 \mathrm{~nm}$, are presented in Table 1.

\section{Discussion}

1. Ni(TMpy-P4) in Poly(dG-dC) 2. Ni(TMpy-P4) is known to be intercalated between base pairs in poly $(\mathrm{dG}-\mathrm{dC})_{2}$, as a 4-coordinate species. ${ }^{47-49}$ Double-exponential kinetics of absorption changes (Figure 2) observed for this complex can be reliably interpreted in terms of formation (first step of decay, $\tau$ $\leq 10 \mathrm{ps}$ ) and decay (second step of decay, $\tau=350 \pm 20 \mathrm{ps}$ ) of the metal-centered ${ }^{3} \mathrm{~B}_{1 \mathrm{~g}}$ excited $(\mathrm{d}, \mathrm{d})$ state, according to the general scheme of excitation relaxation for diamagnetic 4-coordinate Ni porphyrins ${ }^{19,20,30-33}$ (see Figure 1A). Since this transient species is the only one prominent long-lived photoinduced species detected in TA studies, we can also reliably

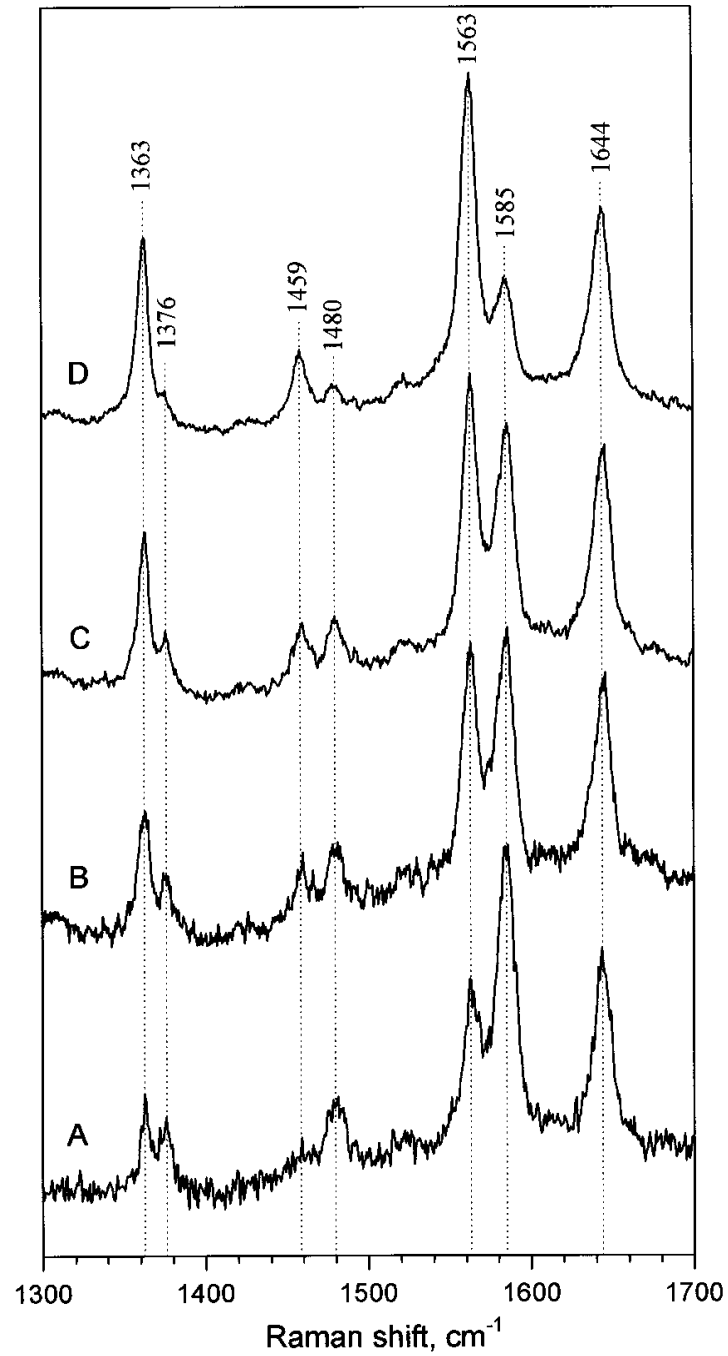

Figure 7. Transient RR spectra of Ni(TMpy-P4) in poly $(\mathrm{dG}-\mathrm{dC})_{2}$, recorded with excitation at $436 \mathrm{~nm}$. Incident power density of laser flux successively increases from spectrum $\mathrm{A}\left(I_{\mathrm{ex}} \approx 10^{6} \mathrm{~W} / \mathrm{cm}^{2}\right)$ to spectrum $\mathrm{D}\left(I_{\mathrm{ex}} \approx 10^{8} \mathrm{~W} / \mathrm{cm}^{2}\right)$.

link it to the transient Raman bands $v_{\mathrm{i}}^{*}$ arising in RR spectra at high excitation power (Figure 7, Table 1).

Indeed, the (d,d) nature of this transient species is confirmed by both TA and RR data. First, its absorption profile (Figure $3 \mathrm{~B}$ ) is typical for the ${ }^{3} \mathrm{~B}_{1 \mathrm{~g}}$ excited state of 4-coordinate $\mathrm{Ni}$ porphyrins, ${ }^{30-34}$ which exhibits a clear red shift from the corresponding ground-state absorption profile, in keeping approximately the same shape. Second, the lifetime of the longlived transient species is also typical for the ${ }^{3} B_{1 g}$ excited (d,d) state of 4-coordinate Ni porphyrins. At last, transient RR spectra recorded at high excitation power (Figure 7) contain prominent additional Raman lines $v_{2}{ }^{*}, v_{3}^{*}$, and $v_{4}{ }^{*}$ pairing their groundstate counterparts with a downward frequency shift of 12-22 $\mathrm{cm}^{-1}$. Such peculiarities in RR spectra of Ni(TMpy-P4)- poly$(\mathrm{dG}-\mathrm{dC})_{2}$ complex are consistent with those observed in RR spectra of the excited $(\mathrm{d}, \mathrm{d})$ state for $\beta$-alkyl substituted $\mathrm{Ni}$ porphyrins which were comprehensively investigated in the last decade. ${ }^{21,36-41}$ However, although RR data on photoinduced ligation-state changes have been published for NiTPP in nitrogen-containing organic bases, ${ }^{55-58}$ we could not find in the literature any transient RR spectrum from the excited (d,d) state of 4-coordinate meso-substituted $\mathrm{Ni}$ tetraarylporphyrins.

Using the well-known correlation between the frequencies of the Raman marker bands and the porphyrin core size of TPP metallocomplexes, ${ }^{59}$ we estimated the value of the macrocycle 


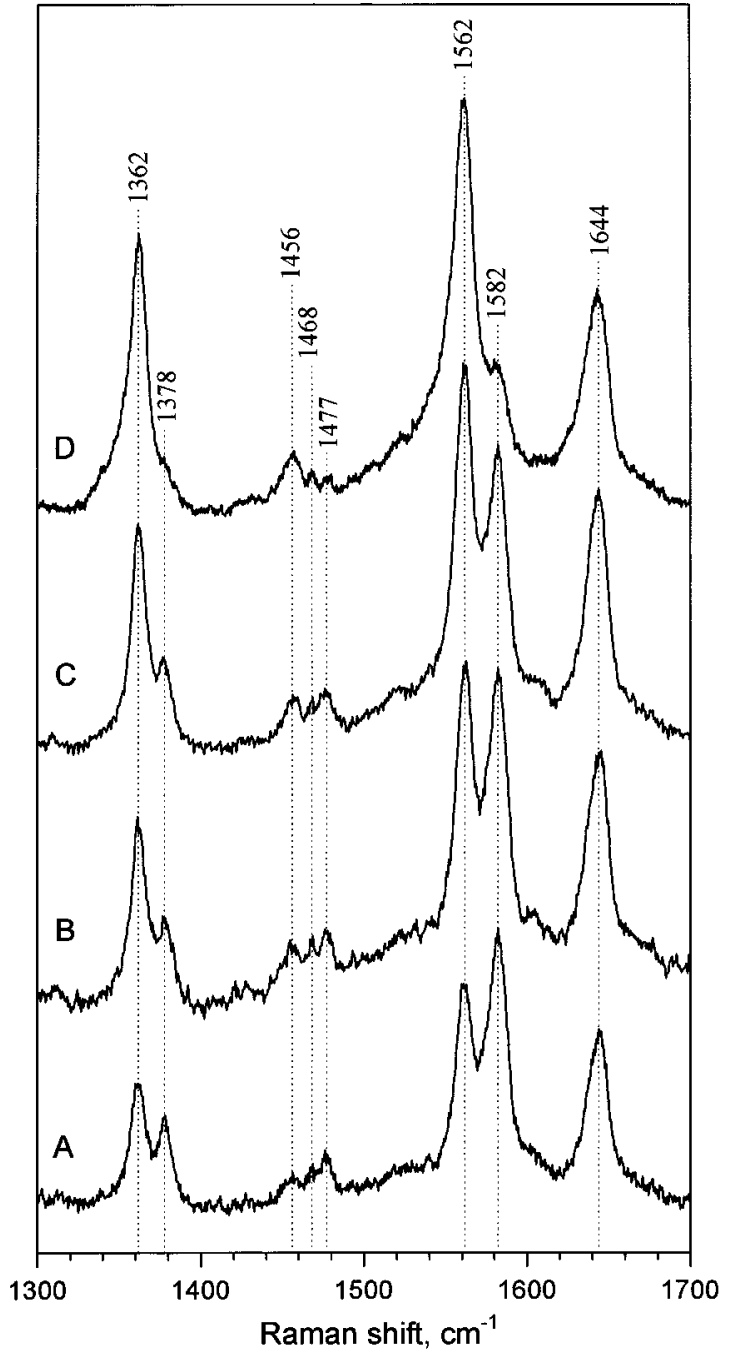

Figure 8. Same as in Figure 7 but for the Ni(TMpy-P4)-poly(dAdT) $)_{2}$ complex.

diameter in the excited $(\mathrm{d}, \mathrm{d})$ state. The center-to-pyrrole distance was found to be $1.98 \AA$ (on the basis of the $v_{2} *$ mode frequency), $1.99 \AA\left(v_{3}^{*}\right)$, and $2.00 \AA\left(v_{4} *\right)$, which gives an average value of $1.99 \AA$. However, this value should only be considered as approximative since, if we apply the same procedure to the ground-state wavenumber values $v_{\mathrm{i}}$, the core diameter would be estimated as $1.91 \AA\left(v_{2}\right), 1.93 \AA\left(v_{3}\right)$, and $1.90 \AA\left(v_{4}\right)$, while the core size real value of Ni(TMpy-P4) is known to be $1.955 \AA$ from crystallographic data. ${ }^{60}$ In any case, the wavenumbers of the downward shifted Raman marker bands reveal quite large porphyrin core expansion of $0.06-0.1 \AA$ in the excited $(d, d)$ state of the porphyrin when intercalated in poly$(\mathrm{dG}-\mathrm{dC})_{2}$, this being necessary to accommodate the increased electron density in the $d_{x^{2}-y^{2}}$ metal orbital.

Concerning the nature of the first transient species, generated within a femtosecond time scale after photoexcitation, our data are not sufficient to state a definite conclusion. (Note also that we cannot observe the femtosecond kinetics of creation either because of insufficient time resolution, and its decay time is estimated to be $\leq 10 \mathrm{ps}$.) Owing to the spectral similarities of absorption bands from the ground and both transient states (Figure 3), the first transient species may be associated with the ${ }^{1} B_{1 g}$ excited $(d, d)$ state. This assignment is quite plausible since it allows the ultrafast radiationless transition ${ }^{1} \mathrm{Q} \rightarrow{ }^{1} \mathrm{~B}_{1 \mathrm{~g}}$ from the $\left(\pi, \pi^{*}\right)$ to the $(\mathrm{d}, \mathrm{d})$ electronic state subsystems to be explained in a consistent way in terms of an allowed transition between excited states of same multiplicity. However, on the

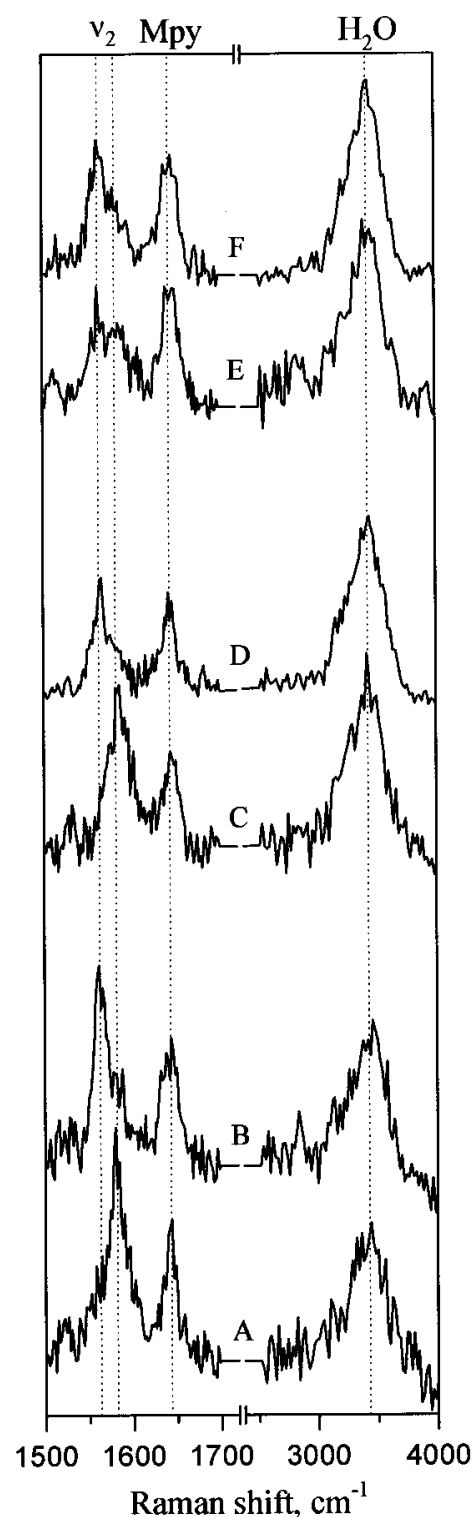

Figure 9. RR spectra of $\mathrm{Ni}(\mathrm{TMpy}-\mathrm{P} 4)$ in the region of the $v_{2}$ line, normalized on the water band at ca. $3430 \mathrm{~cm}^{-1}$. Spectra A and B concerns the complex with poly $(\mathrm{dA}-\mathrm{dT})_{2},\left(\mathrm{~A}\right.$, low $I_{\mathrm{ex}} ; \mathrm{B}$, high $I_{\mathrm{ex}} ; \lambda_{\mathrm{ex}}$ $=427 \mathrm{~nm})$, spectra $\mathrm{C}$ and $\mathrm{D}$ concerns the complex with poly $(\mathrm{dG}-\mathrm{dC})_{2}$ $\left(\mathrm{C}\right.$, low $I_{\mathrm{ex}} ; \mathrm{D}$, high $\left.I_{\mathrm{ex}} ; \lambda_{\mathrm{ex}}=427 \mathrm{~nm}\right)$, and spectra $\mathrm{E}$ and $\mathrm{F}$ concerns the free molecule in a phosphate buffer $\left(\mathrm{E}\right.$, low $I_{\mathrm{ex}} ; \mathrm{F}$, high $I_{\mathrm{ex}} ; \lambda_{\mathrm{ex}}=$ $418 \mathrm{~nm})$.

basis of our experimental data we cannot rule out the existence of other possible physical processes, namely processes of vibrational heating/cooling, ${ }^{34,35,40}$ conformational changes, ${ }^{39}$ and formation/decay of $\mathrm{T}_{1}$ state, as already stated in the Introduction.

The absence of any long-lived component having decay time $\gg 1 \mathrm{~ns}$ in the relaxation kinetics allows one to assume that photoinitiated processes of axial ligand binding/release (formation and decay of ${ }^{3} \mathrm{~B}_{1 \mathrm{~g}}(\mathrm{~L})_{2}$ state in Figure 1A) do not occur in $\mathrm{Ni}(\mathrm{TMpy}-\mathrm{P} 4)-$ poly $(\mathrm{dG}-\mathrm{dC})_{2}$ complex, so that no transient 5or 6-coordinate Ni porphyrin species is generated after photoexcitation. This implies that, during the excited-state lifetime, intercalated Ni(TMpy-P4) is not accessible to water molecules which could in principle be possible extra axial ligands, as it can occur for free Ni(TMpy-P4) in a water buffer.

2. Ni(TMpy-P4) in Poly(dA-dT $)_{2}$. The photoinduced behavior of Ni(TMpy-P4) - poly(dA-dT $)_{2}$ complex is much more complicated than that of the previous complex. Complicated relaxation kinetics observed in TA, in which at least 4 decay components can be separated (Figure 4), supports the existence 


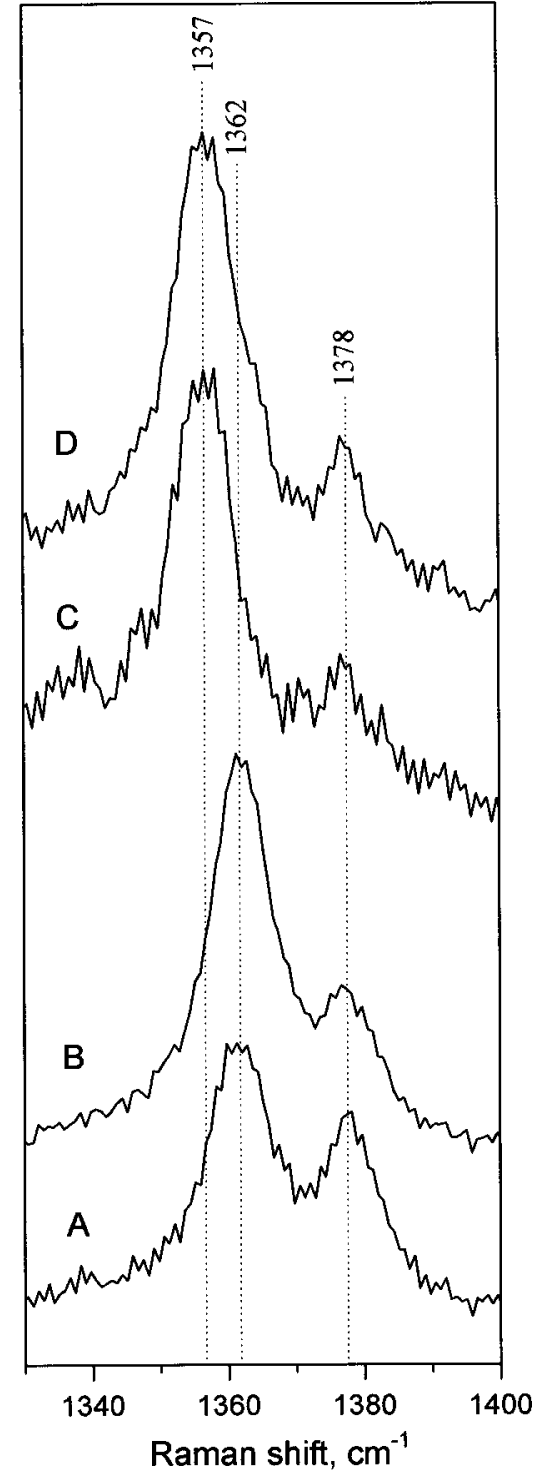

Figure 10. Comparative RR spectra of Ni(TMpy-P4) in poly(dA-dT) (A, "low" $I_{\mathrm{ex}} \approx 10^{6} \mathrm{~W} / \mathrm{cm}^{2} ; \mathrm{B}$, "high" $I_{\mathrm{ex}} \approx 2 \times 10^{7} \mathrm{~W} / \mathrm{cm}^{2}$ ) and in a phosphate buffer (C and D, excitation intensities were equal to those of $\mathrm{A}$ and $\mathrm{B}$, respectively) in the region of the $v_{4}$ line (excitation wavelength, $436 \mathrm{~nm})$.

of more than one type of localization for Ni(TMpy-P4) in A-T sequences, as suggested earlier on the basis of unusual $\mathrm{CD}$ and RR features of this complex. ${ }^{47-52}$ Indeed, literature data ${ }^{29-33}$ indicate that 4-coordinate $\mathrm{Ni}$ porphyrins in a noncomplexing environment exhibit two-phase excited-state decay kinetics having considerably different time constants, i.e. $\leq 10 \mathrm{ps}$ and a few hundreds of picoseconds. Let us remember that the same kinetic picture was observed for the Ni(TMpy-P4)-poly(dG$\mathrm{dC})_{2}$ complex discussed above, where only one type of porphyrin localization (intercalation) was unambiguously established. On the other hand, the existence of at least two types of $\mathrm{Ni}(\mathrm{TMpy}-\mathrm{P} 4)$ binding modes to poly $(\mathrm{dA}-\mathrm{dT})_{2}$ could seriously complicate the OD decay kinetics, if these two types of $\mathrm{Ni}$ (TMpy-P4) complexes have different lifetimes for the transient states populated during excitation relaxation. This suggestion is quite plausible since the lifetime of the ${ }^{3} \mathrm{~B}_{1 \mathrm{~g}}$ state of $\mathrm{Ni}$ porphyrins in organic solvents is solvent- (i.e. environment-) dependent. ${ }^{61}$ In this case, even simple summation of two pairs of different decay kinetics may result in a very complicated wavelength-dependent kinetic picture, and this is indeed the case for Ni(TMpy-P4)-poly(dA-dT) $)_{2}$ complexes (Figure 4).
Long-lived components ( $\tau \gg 1 \mathrm{~ns}$ ) in the relaxation kinetics for this complex (long-decay "tails" of curves in Figure 4A,B) are well-known photophysical markers of the existence of axial ligand binding/release photoprocesses ${ }^{30-33}$ (formation and decay of ${ }^{3} \mathrm{~B}_{1 \mathrm{~g}}(\mathrm{~L})_{2}$ state in Figure 1A). This implies that photoexcited $\mathrm{Ni}(\mathrm{TMpy}-\mathrm{P} 4)$, when complexed with A-T, is at least partially accessible for other ligand molecules and that some amount of nonequilibrated and axially ligated 5- or 6-coordinate Ni(TMpyP4) species is photogenerated. However, as already mentioned in the Results, the shape of the absorption profile originating from the long-lived fourth transient species (Figure 5C) also contains a considerable contribution from the ground state absorption; this indicates that the yield of formation of an axially ligated species is low.

Most Parts of A-T Interacting Porphyrins Remain 4-Coordinate. RR studies of $\mathrm{Ni}(\mathrm{TMpy}-\mathrm{P} 4)-\mathrm{poly}(\mathrm{dA}-\mathrm{dT})_{2}$ complex fully support the conclusions derived from TA data. As already mentioned in the Results, RR spectra of Ni(TMpy-P4) complexed with G-C (Figure 7) and A-T sequences (Figure 8) exhibit very similar power-dependent features. In both cases prominent counterparts of the $v_{2}, v_{3}$, and $v_{4}$ porphyrin groundstate marker lines arise at high excitation power, the wavenumbers of the excited-state $v_{\mathrm{i}}^{*}$ lines being very close for both polynucleotides (Table 1). The dynamic behavior of both systems in a saturated nanosecond laser field is also quite similar (Figure 9). All of this supports the major part of Ni(TMpy$\mathrm{P} 4)$ complexed with poly $(\mathrm{dA}-\mathrm{dT})_{2}$ being 4-coordinated, the intramolecular ${ }^{3} \mathrm{~B}_{1 \mathrm{~g}}$ excited $(\mathrm{d}, \mathrm{d})$ state playing a dominant role in the relaxation processes, like in the case of the G-C complex. However, a more careful examination shows that the RR spectra of the complex with A-T contains additional features to those of the complex with G-C, the most evident being a second satellite for the $v_{3}$ line at $1468 \mathrm{~cm}^{-1}$ in the former (Figure 8) which is absent in the latter (Figure 7). In addition, in the highpower spectrum of the A-T complex (Figure 8D), both $v_{2}-v_{2}{ }^{*}$ and $v_{4}-v_{4} *$ pairs of lines are less resolved than in the spectrum of the G-C complex (Figure 7D), although experimental conditions were the same. All of this can reasonably be explained by the occurrence of some additional (presumably ligated) species contributing to the spectrum of Ni(TMpy-P4)poly $(\mathrm{dA}-\mathrm{dT})_{2}$.

Comparative RR study of Ni(TMpy-P4) complexed with polynucleotides and free in a phosphate buffer permitted spectra provided by the ${ }^{3} \mathrm{~B}_{1 \mathrm{~g}}$ excited state of the 4-coordinate porphyrin and by the ${ }^{3} \mathrm{~B}_{1 \mathrm{~g}}(\mathrm{~L})_{2}$ ground state of the 6-coordinate complex to be reliably distinguished. Indeed, the $v_{4}$ porphyrin mode, known as an oxidation state and $\pi$-electron density marker line, ${ }^{59}$ is not only sensitive to the porphyrin core expansion which occurs to accommodate the d-electron promotion from the $\mathrm{d}_{z^{2}}$ to the $\mathrm{d}_{x^{2}-y^{2}}$ orbitals but also very sensitive to the donation of electron density from axial ligands to the central metal ion and, through this, to the interaction between the metal $d_{p}$ and the porphyrin $\mathrm{e}_{\mathrm{g}}{ }^{*}$ orbitals. This can account for the $19-20 \mathrm{~cm}^{-1}$ frequency shift between the $v_{4}$ mode of 4-coordinate species (electronic state ${ }^{1} \mathrm{~A}_{1 \mathrm{~g}}$, Figure 7A, Table 1) and its $v_{4}{ }^{\prime}$ counterpart of the 6-coordinate species in water (electronic state ${ }^{3} \mathrm{~B}_{1 \mathrm{~g}}(\mathrm{~L})_{2}$, Figure 10C, Table 1, see also ref 49), where both core expansion and electron density donation take place, in comparison to the 13-15 $\mathrm{cm}^{-1}$ shift observed in the $\mathrm{v}_{4}-v_{4} *$ pair for the 4-coordinate species (only core expansion, Figure 7, Table 1). Taking this into account, the bandshape of the $v_{4} *$ mode (Figure $10 \mathrm{~A}, \mathrm{~B})$ reveals that, for $\mathrm{Ni}(\mathrm{TMpy}-\mathrm{P} 4)$ in $\mathrm{A}-\mathrm{T}$ sequence, no transient 6-coordinate species is photogenerated because there is no evidence of any shoulder at the position of the 6-coordinate line at ca. $1357 \mathrm{~cm}^{-1}$. 
TABLE 1: Frequencies $\left(\mathrm{cm}^{-1}\right)$ of Raman Marker Bands in the Ground Electronic State $\left(v_{\mathrm{i}}\right)$, Their 4-Coordinate Excited-State (Rows 1, 2) or 6-Coordinate Ground-State (row 3) Counterparts ( $\left.v_{i}^{\prime}\right)$ for Ni(TMpy-P4) in Various Molecular Environments

\begin{tabular}{|c|c|c|c|c|c|c|}
\hline environment & $v_{2}$ & $v_{2}^{*}\left(v_{2}^{\prime}\right)$ & $v_{3}$ & $v_{3}^{*}\left(v_{3}{ }^{\prime}\right)$ & $v_{4}$ & $v_{4}^{*}\left(v_{4}^{\prime}\right)$ \\
\hline $\operatorname{poly}(\mathrm{dG}-\mathrm{dC})_{2}$ & $1585-1586$ & 1563 & $1480-1481$ & $1459-1460$ & $1376-1377$ & $1363-1364$ \\
\hline poly $(\mathrm{dA}-\mathrm{dT})_{2}$ & $1582-1583$ & $1560-1563$ & $1477-1478$ & $1455-1456^{a}$ & $1377-1378$ & $1362-1364$ \\
\hline water buffer & $1580-1584$ & $(1560-1561)$ & $1479^{b}$ & $\left(1456^{b}\right)$ & $1377-1378$ & $(1356-1358)$ \\
\hline
\end{tabular}

${ }^{a}$ There exists a second satellite at $1468 \mathrm{~cm}^{-1} \cdot{ }^{b}$ Data from ref 49 .

Minor Part of A-T Bound Porphyrins Participates in Photoinduced Binding/Release Processes. However, since a photoinduced ligation process was reliably detected in TA measurements, we now assume that a 5-coordinate species with one axial ligand attached to the central $\mathrm{Ni}$ ion can account for the whole set of data obtained for Ni(TMpy-P4)-poly(dA-dT) $)_{2}$ complex. Indeed, for nonequilibrated 5-coordinate species, the downward frequency shifts of the porphyrin marker bands are expected to be much less pronounced than in the case of 6-coordinate species and, therefore, these bands can be partially hindered by the $v_{\mathrm{i}}^{*}$ bands from the excited $(\mathrm{d}, \mathrm{d})$ state of 4-coordinate species.

Power-induced transformations of Raman spectra in a saturated nanosecond laser field support the assumption that the yield of formation of axially ligated $\mathrm{Ni}(\mathrm{TMpy}-\mathrm{P} 4)$ is low. Indeed, transient RR spectra of both complexes with G-C (Figure 9D) and A-T sequences (Figure 9B) were recorded at approximately the same excitation power. The relative intensities of the $v_{2} *$ Raman lines at ca. $1563 \mathrm{~cm}^{-1}$, normalized on the water band, do not significantly differ for both complexes (note that the difference in the resonance enhancement of Raman bands has to contribute to this intensity difference), whereas the lifetimes of the most long-lived transient species are very different: $350 \mathrm{ps}$ for Ni(TMpy-P4)-poly(dG-dC $)_{2}$ and $\gg 1 \mathrm{~ns}$ for $\mathrm{Ni}(\mathrm{TMpy}-\mathrm{P} 4)-$ poly $(\mathrm{dA}-\mathrm{dT})_{2}$ complexes. This can be consistently explained only if we assume that the contribution from the axially ligated species, with nanosecond lifetime, to the spectrum presented in Figure 9B is small.

At this step of the discussion, partial conclusions can be settled: the major part of $\mathrm{Ni}$ porphyrin molecules exists as a 4-coordinate species, having the "normal" route of excitation relaxation via the long-lived (hundreds of $\mathrm{ps}$ ) ${ }^{3} \mathrm{~B}_{1 \mathrm{~g}}$ excited state. On the other hand, a minor part of the molecules participates in photoinduced binding/release processes, thus involving a nonstationary 5-coordinate $\mathrm{Ni}$ porphyrin species having a lifetime $\gg 1 \mathrm{~ns}$. Let us consider now in more detail the possible geometrical structures which can be proposed on the basis of these photophysical data.

Geometrical Considerations. Three types of Ni(TMpy-P4) localization in A-T sequences can be considered in the case of a dominant 4-coordinate porphyrin species inaccessible to surrounding water molecules: (i) intercalation, (ii) outside stacked aggregation, and (iii) edge-on binding in the minor groove of the double helix.

(i) Although intercalation is fully consistent with our photophysical data, it can hardly be proposed (but not completely ruled out) as a major type of localization after consideration of stationary absorption spectra. Intercalated Ni(TMpy-P4) complex (for instance in G-C sequences) is characterized by a large hypochromicity $(\% \mathrm{H}=46)$ and a substantial red shift $(\Delta \lambda=$ $14 \mathrm{~nm}$ ) of the Soret band (Figure $3 \mathrm{C}^{49}$ ). However, this is not the case here $\left(\% \mathrm{H}=20, \Delta \lambda=6 \mathrm{~nm}\right.$, Figure $\left.5 \mathrm{D}^{49}\right)$, and there is no peak or shoulder at ca. $435 \mathrm{~nm}$ in the absorption spectrum of the A-T complex, which may support intercalation.

(ii) Outside stacked aggregation along the polynucleotide is also very unlikely as a major type of localization, since the porphyrin concentration is low enough in our experiments to rule out this possibility. (iii) Consequently the edge-on binding of Ni(TMpy-P4) in the minor groove of the A-T sequence, where the porphyrin protrudes into the polynucleotide interior far enough to be screened from the surrounding water molecules, is consistent with all experimental data shown either in the present work or in the literature for this complex.

Concerning the minor part of Ni(TMpy-P4) molecules participating in photoinduced ligand binding/release processes, it is plausible to assume that $\mathrm{Ni}(\mathrm{TMpy}-\mathrm{P} 4)$ is located in a faceon manner in the major groove of poly $(\mathrm{dA}-\mathrm{dT})_{2}$ and can adopt one water molecule as an extra axial ligand, thus involving a 5 -coordinate species. Coordination of $\mathrm{Ni}$ porphyrins was the subject of numerous studies by TA, ${ }^{29-35} \mathrm{RR},{ }^{55-58,62}$ and CD techniques. ${ }^{63}$ It was found that free $\mathrm{Ni}$ porphyrin can exist in solution only as a 4- or 6-coordinate species. However, when the environment causes geometrical restrictions, as it occurs in $\mathrm{Ni}$-reconstituted hemoglobin and myoglobin, the central Ni ion can attach only one ligand molecule, thus yielding a 5-coordinate species. ${ }^{62,63}$ Indeed, the same situation would occur for $\mathrm{Ni}$ (TMpy-P4) externally bound to poly $(\mathrm{dA}-\mathrm{dT})_{2}$ in the major groove: a water molecule can be ligated to the central $\mathrm{Ni}$ ion only at one side, since the other is screened by the polynucleotide. It should also be noted that a carbonyl group of thymine may be considered as a possible candidate for axial liganding, by analogy with the case of $\mathrm{Cu}(\mathrm{TMpy}-\mathrm{P} 4)-$ poly $(\mathrm{dA}-\mathrm{dT})_{2}$ exciplex which was comprehensively studied earlier. ${ }^{23-28}$ However, the affinity for water is much higher for Ni than for $\mathrm{Cu}$ porphyrins, as it is clearly seen in stationary Raman spectra of free metal complexes in buffer solution: Ni(TMpy-P4) exists as a nearly equal mixture of 4- and 6-coordinate species while $\mathrm{Cu}$ (TMpy-P4) is strictly 4-coordinate. ${ }^{48,49}$ Moreover, interaction between excited Ni(TMpy-P4) and CO group of thymine implies geometrical changes for both metalloporphyrin and polynucleotide, ${ }^{26}$ while interaction with water does not because there are always a lot of mobile "small" water molecules nearby the porphyrin $\mathrm{Ni}$ ion. Therefore, although the affinity of Ni(TMpy$\mathrm{P} 4$ ) for $\mathrm{CO}$ group of thymine is not known, it is more likely that water molecules are involved as axial ligands in the 5-coordinate Ni(TMpy-P4)-L complex.

Another question can arise: why cannot a water molecule coordinate to $\mathrm{Ni}(\mathrm{TMpy}-\mathrm{P} 4)$ in its electronic ground state if, according to the proposed type of localization, $\mathrm{Ni}$ ion is permanently accessible to water from one side? We speculate that fixation of Ni(TMpy-P4) by the four positively charged methylpyridyl groups to the double helix decreases its affinity for water in the electronic ground state, so that the building of a stable 5-coordinate complex is energetically unfavorable. Indeed, the 5-coordinate structure seems to be domed to some extent, and extra energy is required to keep such a structure stationary. In addition, photoexcited Ni(TMpy-P4) is supposed to have an increased affinity for axial ligands and thus can more easily attach a water molecule, producing a nonstationary 5-coordinate complex.

3. Ni(TMpy-P4) in a Phosphate Buffer Solution. At last we briefly discuss our results concerning free Ni(TMpy-P4) in a phosphate buffer. Complicated TA kinetics obtained for this complex (Figure 6) certainly has its origin in a simultaneous occurrence of the following two opposite photoprocesses: (a) 
photoattachement of surrounding water molecules to initially 4-coordinate species, and (b) photodissociation of the extraligands from initially 6-coordinate species (see Figure 1). On the basis of these TA kinetics, absorption spectra have been reconstructed at various delays after photoexcitation (not shown). However, those absorption spectra obtained at delays shorter than ca. $1 \mathrm{~ns}$ are difficult to analyze since they contain contributions from excited- and ground-state transient species. At larger delays, e.g. $>1 \mathrm{~ns}$, all of the electronic excited states from both 4- and 6-coordinate species have decayed because their lifetimes are not longer than a few hundreds of picoseconds (refs 30-33 and this work). Therefore, OD changes remaining at $1 \mathrm{~ns}$ can essentially be assigned to nonequilibrated 4- and 6-coordinate species resulting from photoexcitation. Experimental observations support this suggestion: the TA spectrum obtained at $1 \mathrm{~ns}$ delay (not shown) resembles that of the initial ground state, but shows an increased contribution from the 6-coordinate species (Soret band maximum at ca. $440 \mathrm{~nm}$ ) and, correspondingly, a decreased contribution from the 4-coordinate species (Soret band maximum at ca. $420 \mathrm{~nm}$ ). This off-balance mixed state then relaxes in a nanosecond time scale (at least) (see long-lived tails in Figure 6C), this being in agreement with literature data obtained for various $\mathrm{Ni}$ porphyrins in organic solvents. ${ }^{30-33}$

It is noteworthy that transient RR spectra of Ni(TMpy-P4) obtained in a water buffer at various excitation powers show features different from those described for the complexes with both polynucleotides. Figure 9 presents RR spectra of free Ni(TMpy-P4) within the $v_{2}$ line region, recorded at low and high excitation powers (Figure 9E,F, respectively). Although these unsmoothed spectra look noisy, power-induced changes can be noted, consisting in relative intensity redistribution between the RR lines of the initially 4- and 6-coordinate species. However, these photoinduced changes in RR spectra of free Ni(TMpy$\mathrm{P} 4)$ are much less pronounced than in the case of complexes with polynucleotides (Figure 9A-D). It is also worthwhile to note that the ${ }^{3} \mathrm{~B}_{1 \mathrm{~g}}(\mathrm{~L})_{2}$ 6-coordinate line at ca. $1561 \mathrm{~cm}^{-1}$ is dominant in both low- and high-power spectra (Figure 9E,F, respectively), in spite of using $418 \mathrm{~nm}$ excitation close to the absorption maximum of the ${ }^{1} \mathrm{~A}_{1 \mathrm{~g}}$ 4-coordinate species. Here the term "low-excitation power" means a power density of $5 \times$ $10^{5}$ to $10^{6} \mathrm{~W} / \mathrm{cm}^{2}$; such an intensity is high enough to produce a considerable population of the nonequilibrated ${ }^{3} \mathrm{~B}_{1 \mathrm{~g}}(\mathrm{~L})_{2}$ state having a lifetime $\gg 1 \mathrm{~ns}$. This well explains the differences between free Ni(TMpy-P4) RR spectra recorded by us at lowexcitation power using 10-ns laser pulses and those available in the literature obtained with $\mathrm{cw}$ laser excitation. ${ }^{48,49}$ On excitation at $436 \mathrm{~nm}$, i.e. close to the absorption maximum of the ${ }^{3} \mathrm{~B}_{1 \mathrm{~g}}(\mathrm{~L})_{2}$ 6-coordinate species, no observable population increase of ${ }^{1} \mathrm{~A}_{1 \mathrm{~g}}$ 4-coordinate species has been detected in increasing the power density (Figure 10C, D).

Consequently, although the detailed interpretation of the intermediate steps of excitation relaxation for $\mathrm{Ni}(\mathrm{TMpy}-\mathrm{P} 4)$ in a phosphate buffer remains difficult at the moment, our data support the photogeneration of the most long-lived nonequilibrated ${ }^{3} \mathrm{~B}_{1 \mathrm{~g}}(\mathrm{~L})_{2}$ state of the 6 -coordinate species, which plays the dominant role in the relaxation processes. Further studies of free Ni(TMpy-P4) are now in progress and will be submitted for future publication.

\section{Conclusion}

In the current spectroscopic studies, we have obtained the following main results:

(i) For Ni(TMpy-P4)-poly(dG-dC) 2 complexes, a doubleexponential kinetics of photoexcitation relaxation was found, with time constants of $\leq 10$ ps and $350 \pm 20$ ps. The longlived transient species was assigned to the excited intramolecular metal-centered $(\mathrm{d}, \mathrm{d})$ state $\left({ }^{3} \mathrm{~B}_{1 \mathrm{~g}}\right)$ of the 4 -coordinate Ni porphyrin intercalated between $\mathrm{G}-\mathrm{C}$ base pairs.

(ii) For the Ni(TMpy-P4)-poly(dA-dT) $)_{2}$ complexes, four relaxation components can be separated with time constants of $\leq 10 \mathrm{ps}, \sim 100 \mathrm{ps}, \sim 450 \mathrm{ps}$, and $\gg 1 \mathrm{~ns}$. This indicates different Ni(TMpy-P4) localizations within A-T sequence, each species having its own double-exponential kinetics of TA decay and transient RR spectra. Indeed, both TA and RR data show that the major part of $\mathrm{Ni}$ porphyrins exhibits photophysical behavior characteristic for a 4-coordinate species, while a minor part participates in axial binding/release photoprocesses. Possible types of binding of Ni(TMpy-P4) to poly(dA-dT $)_{2}$ are discussed.

(iii) From a comparison between transient RR spectra of free $\mathrm{Ni}(\mathrm{TMpy}-\mathrm{P} 4)$ (in a mere phosphate buffer) and complexed with poly $(\mathrm{dA}-\mathrm{dT})_{2}$, it can be concluded that no 6 -coordinate ${ }^{3} \mathrm{~B}_{1 \mathrm{~g}}$ $(\mathrm{L})_{2}$ species is photogenerated in the Ni(TMpy-P4)- poly(dA$\mathrm{dT})_{2}$ complex. Therefore, possible axial coordination of only one extra ligand molecule (from the surrounding water buffer) to the porphyrin central $\mathrm{Ni}$ ion is proposed.

(iv) in a phosphate buffer, where Ni(TMpy-P4) exists as a ground state equilibrium of both 4- and 6-coordinate species, photoinduced transformations in RR spectra were found to be different from those observed in polynucleotide complexes. Relaxation kinetics provides very fast $(\leq 10 \mathrm{ps})$, intermediate (hundreds of ps) and slow ( $\gg 1 \mathrm{~ns}$ ) components. Although a precise interpretation of the intermediate steps of relaxation is difficult at the moment, both TA and RR data support the hypothesis that the long-lived nonequilibrated ${ }^{3} \mathrm{~B}_{1 \mathrm{~g}}(\mathrm{~L})_{2}$ state of the 6-coordinate Ni(TMpy-P4) plays the dominant role in the relaxation processes.

Acknowledgment. The authors would like to thank Dr. S. M. Bachilo for assistance in software used for picosecond spectrometer control and in simulating kinetic absorption data, and Mr. A. Voroshilov for technical assistance in Raman measurements. This work has been supported in part by the Fundamental Research Foundation of the Republic of Belarus (Grant F-157). For performing this study, V.S.C. and S.G.K. have been personally partly supported by the French Ministry of Foreign Affairs, through the French Embassy in Minsk, Republic of Belarus. Part if this work was supported by a grant from the Netherlands Organization for Scientific Research (Grant NB 70-256) and the "Stichting Universiteitsfonds Twente" to S.G.K. for which S.G.K. and C.O. express their gratitude.

\section{References and Notes}

(1) Fiel, R. J.; Howard, J. C.; Mark, E. N.; Datta-Gupta, N. Nucl. Acids Res. 1979, 6, 3093.

(2) Fiel, R. J. Biomol. Struct. Dyn. 1989, 6, 1259.

(3) Pasternack, R. F.; Gibbs, E. J. Metal-DNA Chemistry; Tullius, T. D., Ed.; ACS Symposium Series No. 402; American Chemical Society: Washington, DC, 1989; p 59.

(4) Raner, G.; Goodisman, J.; Dabrowiak, J. C. Metal-DNA Chemistry; Tullius, T. D., Ed.; ACS Symposium Series No. 402; American Chemical Society: Washington, DC, 1989; p 74.

(5) Marzilli, L. G. New J. Chem. 1990, 14, 409.

(6) Sari, M. A.; Battoni, J. P.; Dupré, D.; Mansuy, D.; Le Pecq, J. B. Biochemistry 1990, 29, 4205.

(7) Groves, J. T.; Farrell, T. P. J. Am. Chem. Soc. 1989, 11, 4998.

(8) Slama-Schwok, A.; Lehn, J.-M. Biochemistry 1990, 29, 7895.

(9) Waring, M. J. Annu. Rev. Biochem. 1981, 50, 159.

(10) Wilson, W. D.; Jones, R. L. Intercalation Chemistry; Whittingham, M. S., Jacobson, A. J., Eds.; Academic Press: New York, 1982; p 445.

(11) Musser, D. A.; Datta-Gupta, N.; Fiel, R. J. Biochem. Biophys. Res. Commun. 1980, 97, 918.

(12) Fiel, R. J.; Datta-Gupta, N.; Mark, E. H.; Howard, J. C. Cancer Res. 1981, 41, 3543. 
(13) Praseuth, D.; Gaudemer, A.; Verlhac, J.-B.; Kraljic, I.; Sissoeff, I.; Guille, E. Photochem. Photobiol. 1986, 44, 717.

(14) Villanueva, A.; Hazen, M. J.; Stockert, J.-C. Experientia 1986, 42, 1269.

(15) Dixon, D. W.; Marzilli, L. G.; Schinazi, R. Ann. N.Y. Acad. Sci.1990, 611, 511. 2810 .

(16) Sessler, J. L.; Cyr, M. J.; Lynch, V. J. Am. Chem. Soc. 1990, 112,

(17) Mastruzzo, L.; Woisard, A.; Ma, D. D. F.; Rizzarzlli, E.; Favre,

A.; Le Doan, T. Photochem. Photobiol. 1994, 60, 316.

(18) Verlhac, J. B.; Gaudemer, A.; Kraljic, I. Nouv. J. Chim. 1984., 8, 401.

(19) Holten, D.; Gouterman, M. Optical Properties and Structure of Tetrapyrroles; Blauer, G., Sund, H., Eds.; de Gruyter: Berlin, 1985; p 64.

(20) Dzhagarov, B. M.; Chirvony, V. S.; Gurinovich, G. P. Laser Picosecond Spectroscopy and Photochemistry Biomolecules; Letokhov, V. S., Ed.; Adam Hilger: Bristol, 1987; Chapter 3.

(21) Apanasevich, P. A.; Chirvony, V. S.; Kruglik, S. G.; Kvach, V. V.; Orlovich, V. A. Laser Applications in Life Sciences; Akhmanov, S. A., Poroshina, M. Yu., Koroteev, N. I., Touletaev, B. N., Eds.; SPIE: Bellingham, WA, 1991; Proc. SPIE 1403, Part I, p 195.

(22) Kruglik, S. G.; Apanasevich, P. A.; Chirvony, V. S.; Kvach, V. V.; Orlovich, V. A. J. Phys. Chem. 1995, 99, 2978.

(23) Turpin, P.-Y.; Chinsky, L.; Laigle, A.; Tsuboi, M.; Kincaid, J. R.; Nakamoto, K. Photochem. Photobiol. 1990, 51, 519.

(24) Chinsky, L.; Turpin, P.-Y.; Al-Obaidi, A. H. R.; Bell, S.; Hester,

R. E. J. Phys. Chem. 1991, 95, 5754.

(25) Strahan, G. D.; Lu, D.; Tsuboi, M.; Nakamoto, K. J. Phys. Chem. 1992, 96, 6450 .

(26) Mojzes, P.; Chinsky, L.; Turpin, P.-Y. J. Phys. Chem. 1993, 97, 4841 .

(27) Turpin, P.-Y.; Chinsky, L.; Mojzes, P. Laser Spectroscopy of Biomolecules; Korppi-Tommola, J. E. I., Ed.; SPIE: Bellingham, WA, 1993; Proc. SPIE 1921, p 361.

(28) Kruglik, S. G.; Galievsky, V. A.; Chirvony, V. S.; Apanasevich, P. A.; Ermolenkov, V. V.; Orlovich, V. A.; Chinsky, L.; Turpin, P.-Y. J. Phys. Chem. 1995, 99, 5732.

(29) Kobayashi, T.; Straub, K. D.; Rentzepis, P. M. Photochem. Photobiol. 1979, 29, 925.

(30) Chirvony, V. S.; Dzhagarov, B. M.; Timinskii, Yu.V.; Gurinovich, G. P. Chem. Phys. Lett. 1980, 70, 79.

(31) Chirvony, V. S.; Dzhagarov, B. M.; Shul'ga, A. M.; Gurinovich, G. P. Dokl. Akad. Nauk SSSR 1981, 259, 144.

(32) Kim, D.-H.; Kirmaier, C.; Holten, D. Chem. Phys. 1983, 75, 305.

(33) Kim, D.-H.; Holten, D. Chem. Phys. Lett. 1983, 98, 584.

(34) Rodriguez, J.; Holten, D. J. Chem. Phys. 1989, 91, 3525.

(35) Rodriguez, J.; Kirmaier, C.; Holten, D. J. Chem. Phys. 1991, 94, 6020

(36) Findsen, E. W.; Shelnutt, J. A.; Ondrias, M. R. J. Phys. Chem. 1988, 92, 307.

(37) Chikishev, A. Yu.; Kamalov, V. F.; Koroteev, N. I.; Kvach, V. V.; Shkurinov, A. P.; Toleutaev, B. N. Chem. Phys. Lett. 1988, 144, 90.
(38) Apanasevich, P. A.; Kvach, V. V.; Orlovich, V. A. J. Raman Spectrosc. 1989, 20, 125.

(39) Courtney, S. H.; Jedju, T. M.; Friedman, J. M.; Alden, R. G.; Ondrias, M. R. Chem. Phys. Lett. 1989, 164, 39.

(40) Sato, S.; Kitagawa, T. Appl. Phys. 1994, B59, 415.

(41) Kruglik, S. G.; Apanasevich, P. A.; Kvach, V. V.; Orlovich, V. A. 5th International Conference on Laser Applications in Life Sciences; Apanasevich, P. A., Koroteev, N. I., Kruglik, S. G., Zadkov, V. N., Eds.; SPIE: Bellingham, WA, Proc. SPIE, Vol. 2370, p 196.

(42) Ake, R. L.; Gouterman, M. Theor. Chim. Acta 1970, 17, 408.

(43) Tsvirko, M. P.; Solov'ev, K. N.; Sapunov, V. V. Optika I Spektroskopija 1974, 36, 335.

(44) Antipas, A.; Gouterman, M. J. Am. Chem. Soc. 1983, 105, 4896.

(45) Aronowitz, Y. J.; Gouterman, M. J. Mol. Spectrosc. 1977, 64, 267.

(46) Pasternack, R. F.; Spiro, E. G.; Teach, M. J. Inorg. Nucl. Chem. 1974, 36, 599.

(47) Pasternack, R. F.; Gibbs, E. J.; Villafranca, J. J. Biochemistry 1983, $22,2406$.

(48) Blom, N.; Odo, J.; Nakamoto, K.; Strommen, D. P. J. Phys. Chem. 1986, $90,2847$.

(49) Schneider, J. H.; Odo, J.; Nakamoto, K. Nucl. Acids Res. 1988, $16,10323$.

(50) Bütje, K.; Schneider, J. H.; Kim, J.-J. P.; Wang, Y.; Ikuta, S.; Nakamoto, K. J. Inorg. Biochem. 1989, 37, 119.

(51) Carvlin, M. J.; Fiel, R. J. Nucl. Acids Res. 1983, 11, 6121

(52) Ford, K.; Fox, K. R.; Neidle, S.; Waring, M. J. Nucl. Acids Res. 1987, 15,2221

(53) Kruglik, S. G.; Otto, C.; Ermolenkov, V. V.; Orlovich, V. A.; Galievsky, V. A.; Chirvony, V. S.; Turpin, P.-Y. Chem. Phys. Lett., submitted.

(54) Li, X.-Y.; Czernuszewicz, R. S.; Kincaid, J. R.; Su, Y. O.; Spiro,

T. G. J. Phys. Chem. 1990, 94, 31.

(55) Kim, D.; Su, Y. O.; Spiro, T. G. Inorg. Chem. 1986, 25, 3988.

(56) Kim, D.; Spiro, T. G. J. Am. Chem. Soc. 1986, 108, 2099.

(57) Findsen E. W., Shelnutt J. A., Friedman J. M., Ondrias M. R. Chem. Phys. Lett. 1986, 126, 465.

(58) Findsen E. W., Alston K., Shelnutt J. A., Ondrias M. R. J. Am. Chem. Soc. 1986, 108, 4009.

(59) Spiro, T. G.; Li, X.-Y. Biological Applications of Raman Spectroscopy; Wiley: New York, 1988; Vol. III, Chapter I, pp 2-37.

(60) Kirner, J. F.; Garofollow, J.; Scheidt, W. R. Inorg. Nucl. Chem. Lett. 1975, 11, 107.

(61) Chirvony, V. S. Unpublished results.

(62) Shelnutt, J. A.; Alston, K.; Ho, J.-Y.; Yu, N.-T.; Yamamoto, T.; Rifkind, J. M. Biochemistry 1986, 25, 620.

(63) Choi, S.; Phillips, J. A.; Ware, W., Jr.; Wittschieben, C.; Medforth, C. J.; Smith, K. M. Inorg. Chem. 1994, 33, 3873.

JP960604I 